\title{
Review Article \\ Methods for Detection of Aflatoxins in Agricultural Food Crops
}

\author{
Alex P. Wacoo, ${ }^{1,2}$ Deborah Wendiro, ${ }^{1}$ Peter C. Vuzi, ${ }^{2}$ and Joseph F. Hawumba ${ }^{2}$ \\ ${ }^{1}$ Microbiology and Biotechnology Centre, Department of Product Development, Uganda Industrial Research Institute, \\ P.O. Box 7086, Kampala, Uganda \\ ${ }^{2}$ Department of Biochemistry and Sports Science, School of Biological Sciences, College of Natural Sciences, \\ Makerere University, P.O. Box 7082, Kampala, Uganda \\ Correspondence should be addressed to Joseph F. Hawumba; jhawumba@cns.mak.ac.ug
}

Received 25 August 2014; Accepted 18 October 2014; Published 13 November 2014

Academic Editor: Zhen Cheng

Copyright (c) 2014 Alex P. Wacoo et al. This is an open access article distributed under the Creative Commons Attribution License, which permits unrestricted use, distribution, and reproduction in any medium, provided the original work is properly cited.

\begin{abstract}
Aflatoxins are toxic carcinogenic secondary metabolites produced predominantly by two fungal species: Aspergillus flavus and Aspergillus parasiticus. These fungal species are contaminants of foodstuff as well as feeds and are responsible for aflatoxin contamination of these agro products. The toxicity and potency of aflatoxins make them the primary health hazard as well as responsible for losses associated with contaminations of processed foods and feeds. Determination of aflatoxins concentration in food stuff and feeds is thus very important. However, due to their low concentration in foods and feedstuff, analytical methods for detection and quantification of aflatoxins have to be specific, sensitive, and simple to carry out. Several methods including thin-layer chromatography (TLC), high-performance liquid chromatography (HPLC), mass spectroscopy, enzyme-linked immune-sorbent assay (ELISA), and electrochemical immunosensor, among others, have been described for detecting and quantifying aflatoxins in foods. Each of these methods has advantages and limitations in aflatoxins analysis. This review critically examines each of the methods used for detection of aflatoxins in foodstuff, highlighting the advantages and limitations of each method. Finally, a way forward for overcoming such obstacles is suggested.
\end{abstract}

\section{Introduction}

1.1. Aflatoxins and Their Metabolism. Aflatoxins are cancerous secondary metabolites produced primarily by Aspergillus flavus and Aspergillus parasiticus in agricultural foodstuff such as peanuts, maize grains, cereals, and animal feeds. Aflatoxins are difuranocoumarin molecules synthesized through the polyketide pathway [1]. Six out of 18 different types of aflatoxins that have been identified are considered important and are designated as $B_{1}, B_{2}, G_{1}, G_{2}, M_{1}$, and $M_{2}$, respectively, [2]. These aflatoxin groups exhibit molecular differences. For example, the B-group aflatoxins $\left(\mathrm{B}_{1}\right.$ and $\left.\mathrm{B}_{2}\right)$ have a cyclopentane ring while the G-group $\left(G_{1}\right.$ and $\left.G_{2}\right)$ contains the lactone ring [3]. Whereas the B-group aflatoxins exhibit blue fluorescence, the G-group exhibits yellow-green fluorescence under ultraviolet (UV) light, thus making the use of fluorescence important in identifying and differentiating between the $B$ and $G$ groups. Aflatoxin $B_{1}$ is the most common $[4]$ and the most widespread $[5,6]$ in the world and accounts for $75 \%$ of all aflatoxins contamination of food and feeds [7]. Aflatoxins $M_{1}$ and $M_{2}$ are hydroxylated products of aflatoxins $B_{1}$ and $B_{2}$, respectively, and are associated with cow milk upon ingestion of $B_{1}$ and $B_{2}$ aflatoxins' contaminated feed. Moreover, once formed from $B_{1}$ and $B_{2}$ forms, aflatoxins $\mathrm{M}_{1}$ and $\mathrm{M}_{2}$ remain stable during milk processing [8].

In order to understand the metabolism of aflatoxins, the biotransformation of aflatoxin $B_{1}$, the most abundant form, has been explored [9-11]. Aflatoxin $\mathrm{B}_{1}$ metabolism takes place in the microsome of the liver and is mediated by mixed function monooxygenases belonging to the cytochrome $\mathrm{P}_{450}$ super family of enzymes [12] (Figure 1). In humans, cytochrome $\mathrm{P}_{450}$ enzymes, CYP1A2 and CYP3A4 [10], catabolize aflatoxin $B_{1}$ through two separate electron transfer oxidation reactions $[9,11,13]$. While CYP1A2 breaks down aflatoxin $B_{1}$ to exoepoxide, endoepoxide, and aflatoxin $\mathrm{M}_{1}$, CYP3A4 breaks down aflatoxin $\mathrm{B}_{1}$ to aflatoxin $\mathrm{B}_{1}$-exo8,9-epoxide and aflatoxin $\mathrm{Q}_{1}$. Aflatoxins $\mathrm{M}_{1}$ and $\mathrm{Q}_{1}$ are not broken any further but are excreted in the urine. Aflatoxin 


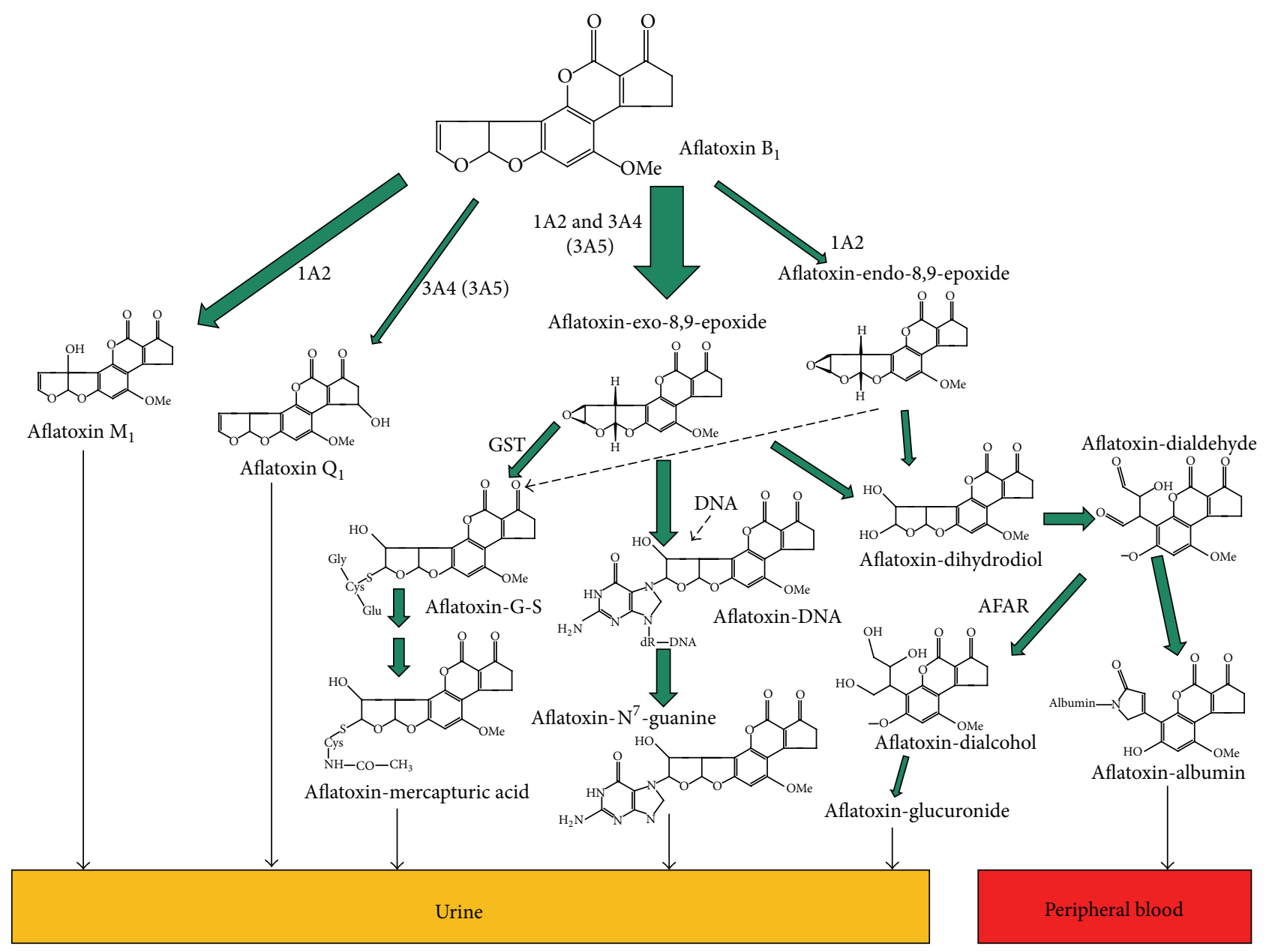

FIGURE 1: Principal metabolism of aflatoxin $\mathrm{B}_{1}$ leading to reactive metabolites and biomarkers. 1A2: CYP1A2; 3A4: CYP3A4; 3A5: CYP3A5; GST: glutathione S-transferase; AFAR: aflatoxin aldehyde reductase; aflatoxin-S-G, aflatoxin-glutathione conjugate (adopted from Wild and Turner, 2002) [9].

$\mathrm{B}_{1}$-exo-8,9-epoxide may be converted either to aflatoxinmercapturic acid via the GST conjugate mediated route or into aflatoxin-glucuronide via the aflatoxin-dihydrodiol route described as follows. The activated form of aflatoxin $\mathrm{B}_{1}$ (exoepoxides and endoepoxides) is detoxified through glutathione $S$-transferase- (GST-) mediated conjugation by using reduced glutathione (GSH) to form $\mathrm{AFB}_{1}$ exoepoxideGSH and endoepoxide-GSH conjugates, respectively [14]. The reactive exoepoxides and endoepoxides also undergo rapid nonenzymatic hydrolysis to aflatoxin $B_{1}-8,9$-dihydrodiol that slowly transforms into a dialdehyde phenolate ion $[9,15]$. Dialdehyde phenolate ion is subsequently hydrolyzed by aflatoxin aldehyde reductase (AFAR) to a dialcohol, in the NADPH-dependent reduction reaction. Thereafter, dialcohol is excreted in urine as aflatoxin-glucuronide [16, 17]. Aflatoxin $B_{1}$ dialdehydes also form Schiff bases with primary amine groups of amino acid residues such as lysine of such a protein as albumin to form aflatoxin $B_{1}$-albumin conjugate [9]. This conjugate persists in the systemic blood as permanent and irreversible aflatoxin $B_{1}$-albumin adducts and is thus considered one of the factors accounting for the low excretion of aflatoxins and their metabolites in urine [18].

1.2. Toxicity of Aflatoxins. From the foregoing (Figure 1), it can be observed that the primary derivatives of aflatoxin $\mathrm{B}_{1}$ biotransformation comprise (a) aflatoxin $\mathrm{M} 1$ and aflatoxin-exo-8,9-epoxide (products of CYP1A2 activity) and (b) aflatoxin $\mathrm{Q}_{1}$ and aflatoxin-exo-8,9-epoxide (products of CYP3A4 activity). Aflatoxins $\mathrm{M}_{1}$ and $\mathrm{Q}_{1}$, although toxic, are less reactive with other molecules and are easily eliminated from the body in the urine [9]. However, aflatoxin $B_{1}$ 8,9-exo-epoxide is a known mutagen, which is extremely electrophilic and covalently reacts with nucleophilic sites of either deoxyribonucleic acid (DNA) or ribonucleic acid (RNA) or proteins [21], thereby introducing mutations that may affect the normal function of cells. The formation of aflatoxin $\mathrm{B}_{1}$-DNA adducts is extremely associated with the carcinogenicity of aflatoxin $B_{1}$. Typically, aflatoxin $B_{1}$ reacts with DNA (methylation) resulting in $\mathrm{G} \rightarrow \mathrm{T}$ transversion 


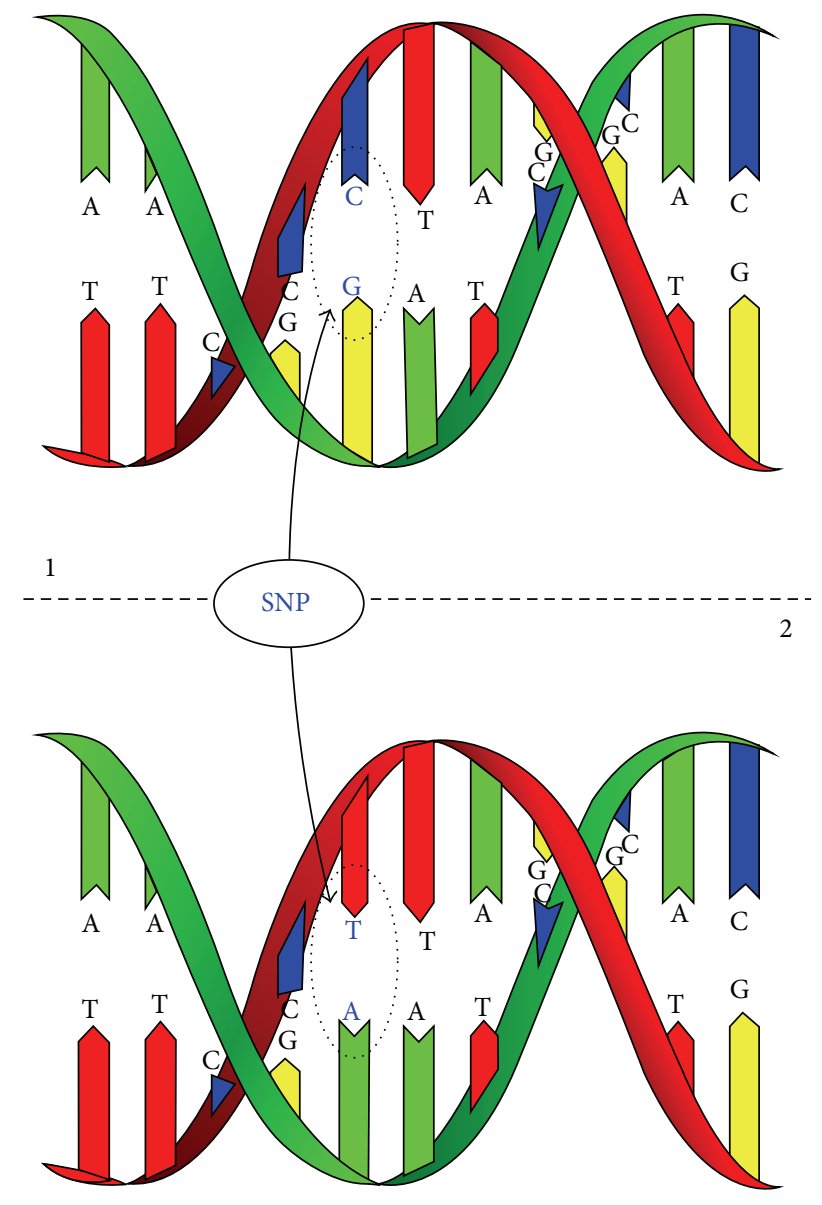

Figure 2: Point mutation of $\mathrm{G} \rightarrow \mathrm{T}$ at codon 249 in the $\mathrm{p} 53$ gene resulting in aflatoxin induced hepatocellular cancer (adopted from Bbosa et al., 2013) [13].

mutation (Figure 2) [22]. Such a mutation has been associated with hepatocellular carcinoma, a type of cancer whereby aflatoxin $\mathrm{B}_{1}$ promotes $\mathrm{AGG} \rightarrow \mathrm{AGT}(\mathrm{Arg} \rightarrow$ Ser) transversion point mutation of p53 gene at codon 249 that alters $p 53$ gene, which is responsible for DNA repair [23]. Apart from $G \rightarrow$ $\mathrm{T}$ transversions, $\mathrm{G} \rightarrow \mathrm{C}$ transversions and $\mathrm{G} \rightarrow \mathrm{A}$ transitions have also been reported [22].

Nucleic acids and proteins interact covalently with aflatoxins and this results in alteration in base sequences in nucleic acids (both DNA and RNA) and in protein structures, leading to impairment of their activity. The highly reactive aflatoxin $\mathrm{B}_{1}-8,9$-exo-epoxide and its hydration product, dihydrodiol, bind covalently to DNA, RNA, and proteins to inhibit protein synthesis [24]. Typically, RNA polymerase and ribosomal translocase have been demonstrated to be inhibited by aflatoxin $B_{1}-8,9$-exo-epoxide [24]. While the epoxide reacts at the $\mathrm{N}^{7}$ position of guanine of both DNA and RNA, the dihydrodiol reacts with the amino groups of the bases forming a Schiff base [25]. Aflatoxin $\mathrm{B}_{1}$ has also been reported to negatively impact carbohydrate metabolism, which results in both the reduction in hepatic glycogen and also the increased blood glucose levels (Figure 3). Notably, the negative effects of aflatoxin $B_{1}$ on carbohydrate metabolism

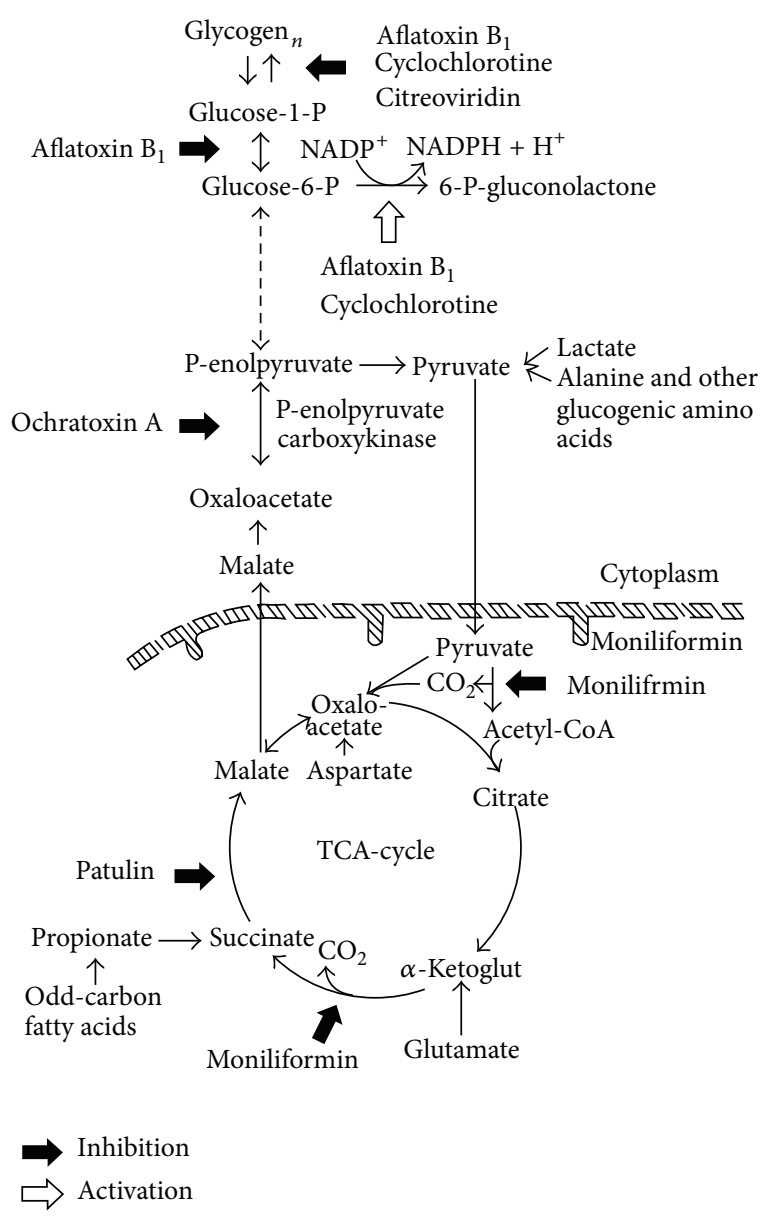

FIGURE 3: Inhibition ofoxidative phosphorylation by aflatoxins (adopted from Kiessling, 1986) [19].

appear to stem from its inhibitory effects of glycogen synthetase and transglycosylase enzymes, which, in turn, brings to a halt glycogen synthesis [19]. Besides, aflatoxin $B_{1}$ also inhibits phosphoglucomutase, an enzyme that reversibly catalyzes the conversion of glucose-6-phosphate into glucose1-phosphate, leading to a decrease in its activity, thereby promoting both the accumulation of glucose 6-phosphate and a decrease in glycogen synthesis. Consequently, excess glucose cannot be stored as glycogen but either accumulates in blood or is converted to glucose-6-phosphate for synthesis of more metabolic intermediates via the pentose phosphate pathway. Other effects of aflatoxins $B_{1}, G_{1}$ and $M_{1}$ include: the inhibition of electron transport system in the mitochondria, specifically, cytochrome oxidase activity (Figure 4) $[19,26]$

Besides inhibition of the electron transport chain, aflatoxins are also good carcinogens. Consequently, the International Agency for Research on Cancer (IARC) of the World Health Organization in 1987 classified aflatoxins and, in 1993, it classified aflatoxin $B_{1}$ as Group 1 carcinogen [26]. Since then, aflatoxins concentration has become one of the most critical indicators of food and feed toxicity. Accordingly, several methods have been developed for the detection and quantification of aflatoxins in agricultural 


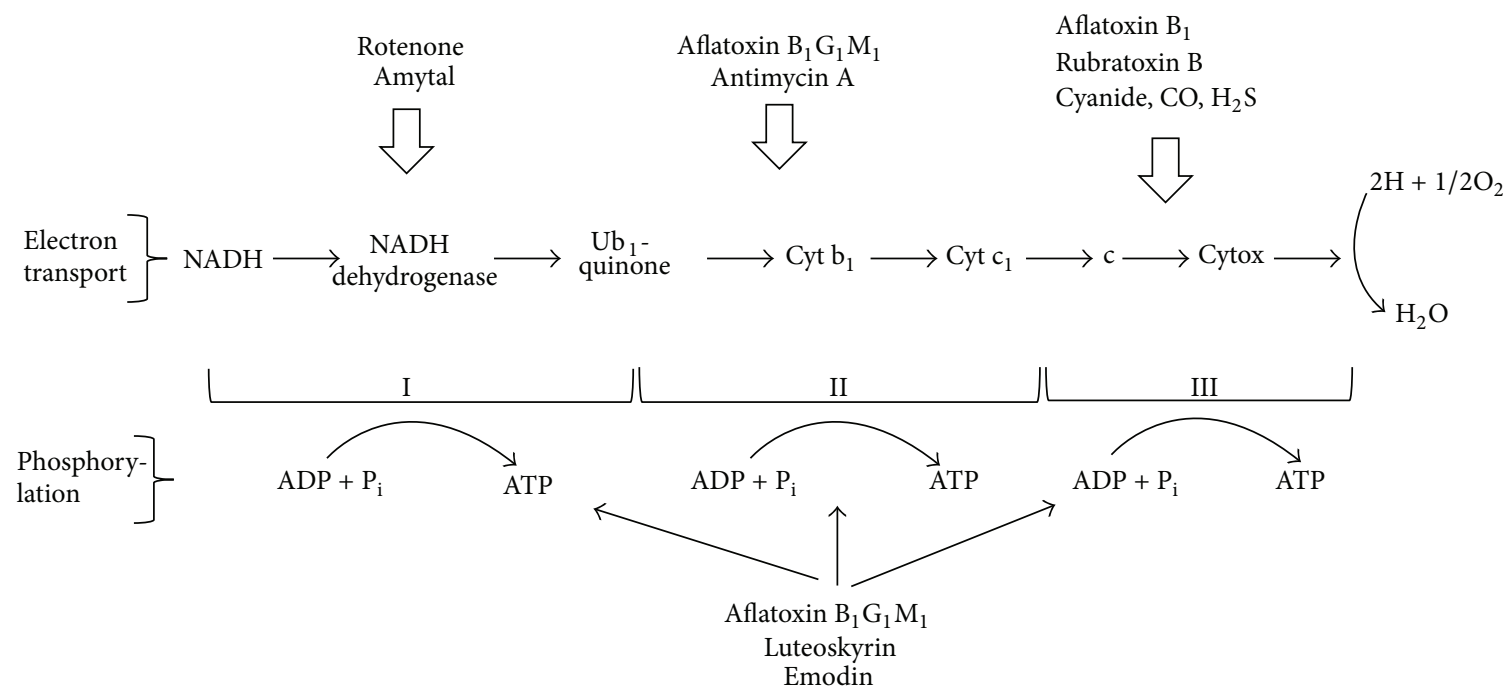

$\longrightarrow$ Uncoupling of oxidative phosphorylation
$\Rightarrow$ Inhibition of electron transport

FIGURE 4: Sites of inhibition of the electron transport chain by aflatoxins (adopted from Kiessling, 1986) [19].

produce and processed food products [27-29]. Basing on the principles of detection, the methods can broadly be grouped into chromatographic, spectroscopic, and immunochemical methods. This review explores the different methods of aflatoxins detection and quantification in food and feed stuff, highlighting their strengths and weaknesses, hence, offering suggestions on how some of the current drawbacks of the methods can be addressed.

\section{Aflatoxins Extraction from Food Samples}

The detection and quantification of aflatoxins in food samples require an efficient extraction step. Aflatoxins are generally soluble in polar protic solvents such as methanol, acetone, chloroform, and acetonitrile. Thus, the extraction of aflatoxins involves the use of these organic solvents such as either methanol or acetonitrile or acetone mixed in different proportion with small amounts of water [46, 47]. Several studies exploring the extraction efficiency of different organic-aqueous solvents have been carried out on the commonly contaminated matrices [48-50] and different results have been reported. Aflatoxin determination based on immunoassay technique requires extraction using mixture of methanol-water $(8+2 \mathrm{v} / \mathrm{v})[48,51]$ because methanol has less negative effect on antibodies compared to other organic solvents such as acetone and acetonitrile.

The extraction of aflatoxins is usually followed by a cleanup step. The common cleanup technique used is immunoaffinity column (IAC) chromatography [52]. This is considered the method of choice for the purification and concentration of aflatoxins [53] before their determination using high-performance liquid chromatography (HPLC). Immunoaffinity column chromatography employs the high specificity and reversibility of binding between an antibody and antigen to separate and purify target analytes from matrices [54]. During sample cleanup, the crude sample extract is applied to the immunoaffinity column containing specific antibodies to aflatoxin immobilized on a solid support such as agarose or silica. As the crude sample moves down the column, the aflatoxin binds to the antibody and is retained onto the column. Another washing step is normally required to remove impurities and unbound proteins. This is achieved by using appropriate buffers and ionic strengths. Thereafter, the aflatoxin is recovered by using such solvents as acetonitrile which breaks the bond between the antibody and the aflatoxin. Table 1 provides a summary of the current analytical methods used in aflatoxin determination. A detailed account of each method is presented in sections that follow below.

\section{Methods for Detection and Quantification of Aflatoxins}

3.1. Chromatographic Methods. Chromatographic techniques are based on the physical interaction between a mobile phase and a stationary phase. The components to be separated are distributed between the two phases (stationary phase and mobile phase) [55]. The mobile phase is usually a fluid that penetrates through or along the stationary bed (liquid or solid). Liquid, gas, and supercritical fluids are currently used as mobile phase and chromatographic techniques derive their names from the nature of the mobile phase: liquid chromatography, gas chromatography, and supercritical fluid chromatography, respectively (Table 1). In practice, the sample to be analyzed is dissolved in the mobile phase and applied as a spot on the stationary phase. The analyte or sample is carried along by the mobile phase and partitions between the solid and liquid stationary phase are called the sorbent. The various constituents in the analytes travel at 
TABLE 1: Comparison of different methods of aflatoxin analysis.

\begin{tabular}{|c|c|c|c|c|c|c|c|}
\hline Method & Need for a label & $\begin{array}{l}\text { Need for } \\
\text { prior sample } \\
\text { preparation }\end{array}$ & LOD & $\begin{array}{l}\text { Multiple } \\
\text { analysis }\end{array}$ & $\begin{array}{l}\text { Need for } \\
\text { skilled } \\
\text { operator }\end{array}$ & Field usage & Reference \\
\hline TLC densitometer & & SPE & $1-20 \mathrm{ng} / \mathrm{Kg}$ & Yes & Yes & No & {$[30,31]$} \\
\hline HPTLC & & $\begin{array}{l}\text { Extraction } \\
\text { only }\end{array}$ & Pictogram & yes & yes & No & {$[32]$} \\
\hline HPLC & & IAC or SPE & & Yes & Yes & No & [33] \\
\hline LC-MS/MS & & $\begin{array}{l}\text { Extraction } \\
\text { only }\end{array}$ & $0.8 \mu \mathrm{g} / \mathrm{Kg}$ & Yes & Yes & No & {$[34]$} \\
\hline Fluorometer & & IAC & $5-5000 \mu \mathrm{g} / \mathrm{Kg}$ & Yes & Yes & No & [35] \\
\hline FTIR & & & $<10 \mu \mathrm{g} / \mathrm{Kg}$ & Yes & Yes & No & [36] \\
\hline RIA & Radio isotope & $\begin{array}{l}\text { Extraction } \\
\text { only }\end{array}$ & $1 \mu \mathrm{g} / \mathrm{Kg}$ & Yes & Yes & No & [37] \\
\hline ELISA & Enzymes & $\begin{array}{l}\text { Extraction } \\
\text { only }\end{array}$ & & Yes & Yes & No & [38] \\
\hline Immunodipstick & Colloidal gold & $\begin{array}{l}\text { Extraction } \\
\text { only }\end{array}$ & $5 \mu \mathrm{g} / \mathrm{Kg}$ & Yes & Yes & Yes & [39] \\
\hline QCMs & & $\begin{array}{l}\text { Extraction } \\
\text { only }\end{array}$ & $0.01-10 \mathrm{ng} / \mathrm{mL}$ & Yes & Yes & No & {$[40,41]$} \\
\hline SPR & & $\begin{array}{l}\text { Extraction } \\
\text { only }\end{array}$ & $3.0-98 \mathrm{ng} / \mathrm{mL}$ & Yes & Yes & No & {$[42]$} \\
\hline OLWS & & $\begin{array}{l}\text { Extraction } \\
\text { only }\end{array}$ & $0.5-10 \mathrm{ng} / \mathrm{mL}$ & Yes & Yes & No & {$[43]$} \\
\hline Electrochemical & & $\begin{array}{l}\text { Extraction } \\
\text { only }\end{array}$ & $2 \mu \mathrm{g} / \mathrm{Kg}$ & Yes & Yes & No & {$[44]$} \\
\hline Electrochemical & & $\begin{array}{l}\text { Extraction } \\
\text { only }\end{array}$ & 1 femtomolar & Yes & Yes & No & [45] \\
\hline
\end{tabular}

different speeds resulting in differential partitioning of the constituents between the mobile and the stationary phases. The most commonly used chromatography techniques for analysis of aflatoxins are thin-layer chromatography (TLC), high-performance liquid chromatography (HPLC), and gas chromatography (GC). Although many of the chromatographic techniques are very sensitive, they require trained skilled technician, cumbersome pretreatment of sample, and expensive apparatus/equipment [56].

3.1.1. Thin-Layer Chromatography (TLC). Thin-layer chromatography was first used by de Iongh et al. [57] and has been regarded by the Association of Official Analytical Chemist (AOAC) as the method of choice since 1990. Thin-layer chromatography is one of the most widely used separation techniques in aflatoxins analysis. It consists of a stationary phase made of either silica or alumina or cellulose immobilized on an inert material such as glass or plastic, called the matrix. The mobile phase is comprised of methanol: acetonitrile: water mixture [58], which carries the sample along as it moves through the solid stationary phase. In TLC, the distribution of aflatoxins between the mobile and stationary phases is based primarily on differences in solubility of the analytes in the two phases. Different analytes, depending on their molecular structures and interaction with the stationary and mobile phases, either adhere to the stationary phase more or remain in the mobile phase, thereby allowing for quick and effective separation. Thin-layer chromatography has been widely used in the determination of aflatoxins in different foods [5961] and as low as $1-20 \mathrm{ppb}$ of aflatoxins has been reported [62]. The advantage of using the TLC method is that it can detect several types of mycotoxins in single test sample [30, 62]. Whereas TLC has excellent sensitivities, it also requires skilled technician, pretreatment of sample, and expensive equipment $[8,63]$. In addition, TLC lacks precision due to accumulated errors during sample application, plate development, and plate interpretation. Attempts to improve TLC have led to the development of automated form of TLC, called the high-performance thin-layer chromatography (HPTLC). The HPTLC has since overcome the problems associated with the conventional TLC techniques through automation of sample application, development, and plate interpretation. It is not surprising that currently HPTLC is one of the most efficient and precise methods in aflatoxins analysis [64, 65]. Nevertheless, the requirement for skilled operators, the costs of the equipment coupled with its bulkiness, and the extensive sample pretreatment limit the HPTLC to the laboratory and thus it is inapplicable in field situations.

3.1.2. High-Performance Liquid Chromatography (HPLC). High-performance liquid chromatography (HPLC) is the most popular chromatographic technique for separation 
and determination of organic compounds. About $80 \%$ of organic compounds in the world are determined using HPLC [66]. The HPLC technique makes use of a stationary phase confined to either a glass or a plastic tube and a mobile phase comprising aqueous/organic solvents, which flow through the solid adsorbent. When the sample to be analyzed is layered on top of the column, it flows through and distributes between both the mobile and the stationary phases. This is achieved because the components in the samples to be separated have different affinities for the two phases and thus move through the column at different rates. The liquid (mobile) phase emerging from the column yields separate fractions containing individual components in the sample. In practice, the HPLC technique employs a stationary phase such as $\mathrm{C}-18$ chromatography column, a pump that moves the mobile phase(s) through the column, a detector that displays the retention times of each molecule, and mobile phases (Figure 5).

The sample to be analyzed is usually injected into the stationary phase and the analytes are carried along through the stationary phase by the mobile phase using high pressure delivered by a pump. The analytes are distributed differently within the stationary phase [67] through chemical as well as physical interactions with the stationary and mobile phases [33]. The time at which a specific analyte elutes is recorded by a detector as its retention time. The retention time depends on the nature of the analyte and composition of both stationary and mobile phases [68]. Programmable detectors such as either the fluorescent detector (FLD) or the ultraviolet (UV) detector or the diode array detector (DAD) may be used in the detection and identification of aflatoxins. High pressure liquid chromatography methods used for the determination of aflatoxins in foods include the normal-phase and reversedphase high pressure liquid chromatography techniques [33]. The reversed phase HPLC method is the most widely used for separation and determination of aflatoxins. Occasionally, chemical derivatization of aflatoxins $B_{1}$ and $G_{1}$ may be required to enhance sensitivity of HPLC during analysis since the natural fluorescence of aflatoxins $B_{1}$ and $G_{1}$ may not be high enough to reach the required detection limit [69]. The derivatization reactions of aflatoxin $B_{1}$ with both the acid and halogens are presented in Figure 6. Whilein the first reaction step, the second furan ring of aflatoxin $B_{1}$ is hydrolyzed by trifluoroacetic acid (TFA) into a highly fluorescent aflatoxin $\mathrm{B}_{2} \mathrm{a}$, in the second and the third derivatization reaction steps, bromine and iodine are used as reagent, respectively. They react with aflatoxin $B_{1}$ to form highly fluorescent aflatoxin $B_{1}$ derivatives of these halogens, respectively.

Papadopoulou-Bouraoui et al. [20] compared two postcolumn derivatization methods for the determination of aflatoxins $B_{1}, B_{2}, G_{1}$, and $G_{2}$ by fluorescence detection after liquid chromatographic separation (Figure 7). The results showed that both bromination and irradiation by UV light were suitable for the determination of aflatoxins in various foods and animal feed matrices and both generated comparable results for fluorescence amplification and repeatability. The fluorescence of aflatoxins $B_{1}$ and $G_{1}$ was significantly enhanced after derivatization reaction either by bromination or by irradiation by UV light.
High-performance liquid chromatography provides fast and accurate aflatoxins detection results within a short time. A sensitivity of detection as low as $0.1 \mathrm{ng} / \mathrm{Kg}$ using FLD has been reported [70]. However, the disadvantage of using HPLC for aflatoxins analysis is the requirement of rigorous sample purification using immunoaffinity columns. In addition, HPLC requires tedious pre- and postcolumn derivatization processes to improve the detection limits of aflatoxins $B_{1}$ and $G_{1}[66]$. Therefore, to overcome the challenges associated with derivatization processes in aflatoxins analysis, a modification of the HPLC method, whereby the HPLC is coupled to mass spectroscopy, has been made and is currently employed in the determination of aflatoxin [71]. Since the mass spectrometer requires neither use of UV fluorescence nor the absorbance of an analyte, the need for chemical derivatization of compounds is eliminated. The HPLC-MS/MS uses small amounts of sample to generate structural information and exhibits low detection limits [33]. However, HPLC-MS/MS is bulky and very expensive equipment which can only be operated by trained and skilled personnel. Besides, this also limits its use to only laboratory environment and not field conditions.

3.1.3. Gas Chromatography (GC). In gas chromatography, the mobile phase is a carrier gas and the stationary phase is a liquid coated onto inert solid particles. As with other chromatographic methods, sample analysis by GC is based primarily on differential partitioning of analytes between the two phases. The stationary phase consists of inert particles coated with a layer of liquid and is normally confined to a long stainless steel or glass tube called the column, which is maintained at appropriate temperature. The sample to be analyzed is vaporized into gaseous phase and carried through the stationary phase by a carrier gas. The different chemical constituents in the sample will distribute themselves between the mobile phase and the stationary phase. The components of the samples mixture with higher affinity for the stationary phase are retarded in their movement through the column, while those of low affinity pass through the column less impeded. For that matter, each component of the analyte should have a specific partition coefficient, which, in turn, will govern its rate of passage through the column [72]. Once separation has been achieved, the detection of the volatile products is carried out using either a flame ionization detector (FID) or an electron capture detector (ECD) and mass spectrometer (MS) [73]. Owing to their nonvolatility in nature, aflatoxins may need derivatization in order to be detected [74]. Gas chromatography, however, is less common in commercial analysis of aflatoxins due to the existence of other cheaper chromatographic methods [75]. Besides, gas chromatography also requires a preliminary cleanup step before analysis and it is therefore limited to analysis of a few mycotoxins, such as A-trichothecenes and B-trichothecenes. Even in such analyses, the GC has such disadvantages as nonlinearity of calibration curves, drifting responses, memory effects from previous samples, and high variation in reproducibility and repeatability [76]. 


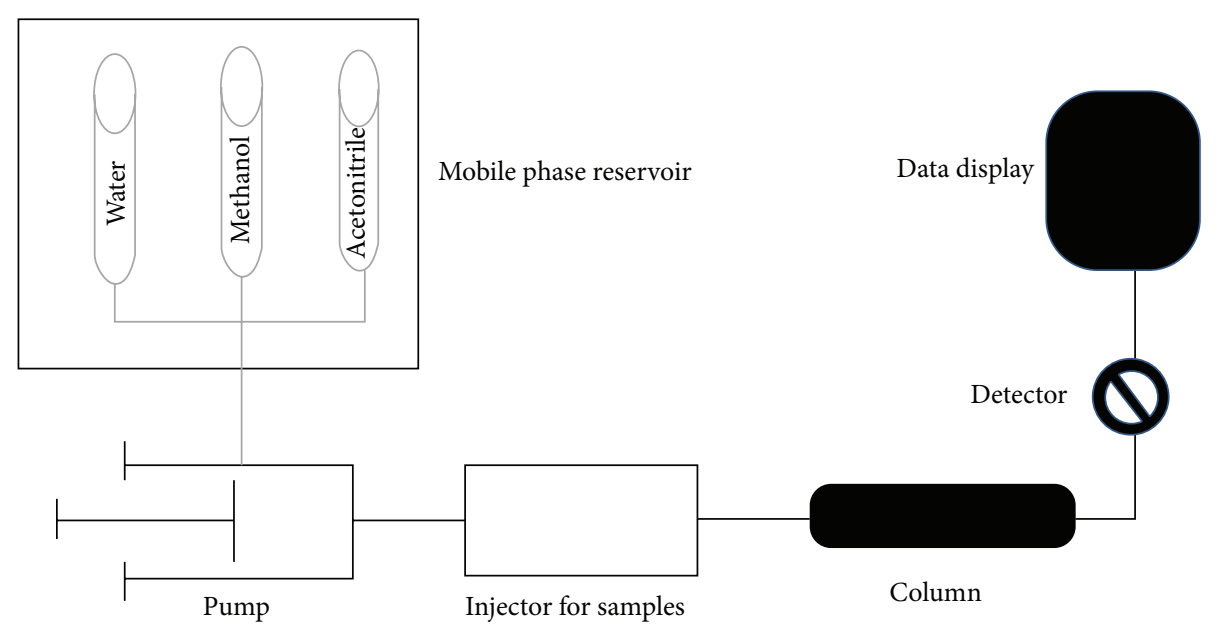

FIGURE 5: Schematic diagram of components of high-performance liquid chromatography.

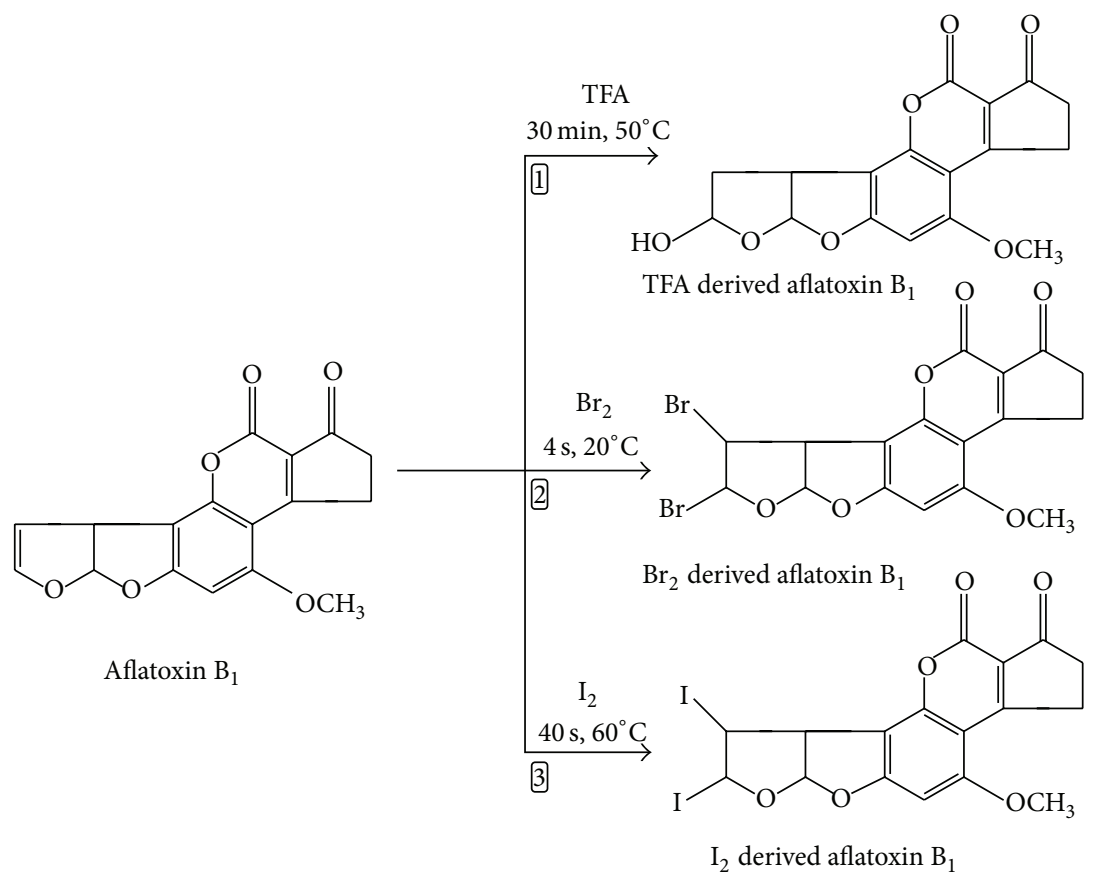

FIgURE 6: Derivatization of aflatoxin $B_{1}$ with trifluoroacetic acid, bromine, and iodine [6].

\subsection{Spectroscopic Methods}

3.2.1. Fluorescence Spectrophotometry. Absorption in the ultraviolet-visible region is very important procedure for unraveling the molecular structures of materials. However, for some molecules, the process of absorption is followed by emission of light of different wavelength. In other words, such molecules are said to fluoresce. Fluorescence is very important in the characterization and analysis of molecules that emit energy at specific wavelengths and has been used to analyze aflatoxins in grains and raw peanut [77]. The fluorometric method can quantify aflatoxin from 5 to $5000 \mathrm{ppb}$ within less than 5 minutes. However, for better analysis of aflatoxins using fluorometry, derivatization may be required to improve on the fluorescence of aflatoxins. The limit of detection is also slightly higher than the limit of $4 \mu \mathrm{g} / \mathrm{Kg}$ set for European settings and thus may not be good for analyzing samples from products to be exported to Europe.

3.2.2. Frontier Infrared Spectroscopy. Another spectroscopic method useful in aflatoxin analysis is infrared spectroscopy (IR). Infrared spectroscopy relies on the alteration in molecular vibrations upon irradiation with infrared radiations. The vibrations by the bonds within the molecule can be measured. Since the atomic size, bond length, and bond strength vary greatly from molecule to molecule, the rate at which a particular bond absorbs infrared radiation will 


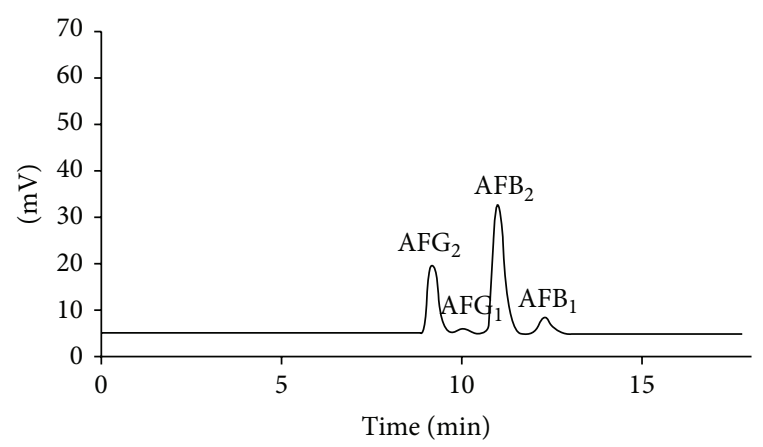

(a)

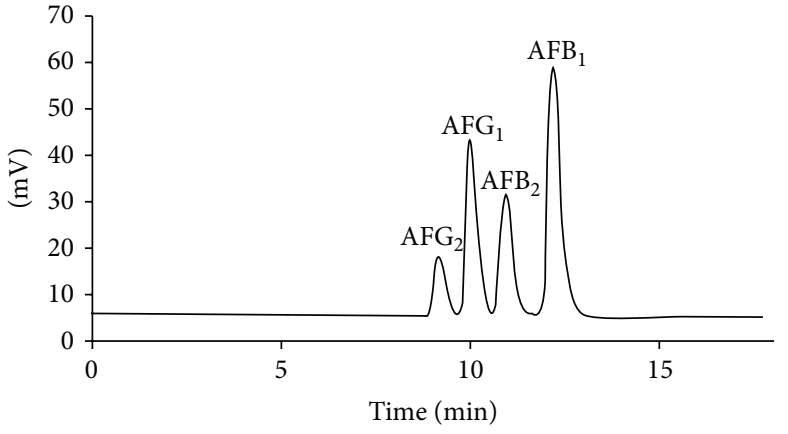

(b)

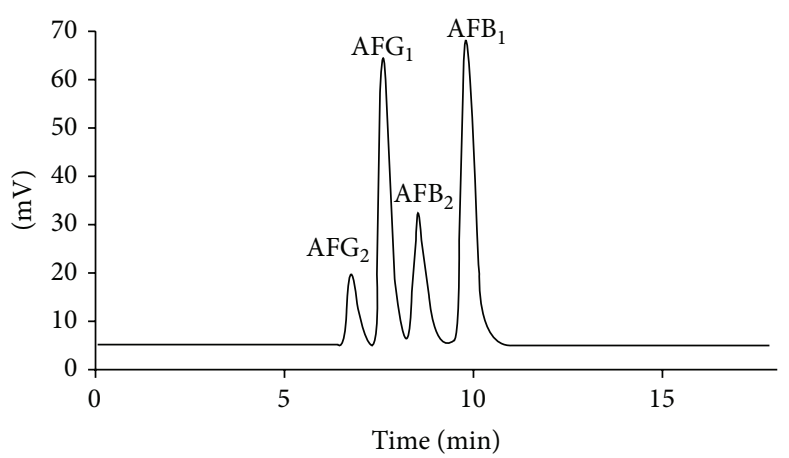

(c)

Figure 7: Chromatograms obtained for a mixed aflatoxin standard ( $\mathrm{AFB}_{1}$ and $\mathrm{AFG}_{1}$, each at $20 \mathrm{ng} / \mathrm{mL}$, and $\mathrm{AFB}_{2}$ and $\mathrm{AFG}_{2}$, each at $\left.4 \mathrm{ng} / \mathrm{mL}\right)$ by using (a) no derivatization, (b) $\mathrm{PCD}_{\mathrm{UV} 2}$, and (c) $\mathrm{PCD}_{\mathrm{EC}}$ (adopted from Papadopoulou-Bouraoui et al., 2002) [20].

differ from bond to bond and in the mode of vibration. For instance, the various bonds of organic molecules should vibrate at different frequencies, in tandem with the type of bond excited. So when an infrared spectrometer is used in the analysis of a compound, infrared radiations covering a range of different frequencies are passed through the sample and the radiant energy absorbed by each type of bonds in the molecules is measured. A spectrum is then produced normally consisting of plot of $\%$ transmittance against the wave number. No two organic compounds have the same infrared spectrum and thus individual pure compounds can be identified by examination of their infrared spectra. The use of Fourier transform infrared spectroscopy which employs attenuated total internal reflectance has been reported for analysis of aflatoxins in peanuts and peanut cake by Mirghani et al. [78]. Pearson et al. [36] also used transmittance and reflectance spectroscopy to detect aflatoxin in single corn kernels. More than $95 \%$ of the kernels analysed were correctly categorized as having either high $(>100 \mathrm{ppb})$ or low $(<10 \mathrm{ppb})$ concentrations of aflatoxins.

3.3. Immunochemical Methods. Immunochemical techniques rely on the specificity of binding between antibodies and antigens. The high affinity and specificity of antibodies for antigens have been used in the development of the various immunochemical methods. Moreover, specific binding is not limited to antigens and antibodies, but rather, receptors and ligands, too, exhibit such affinity as well as high specificity [79]. The formation of either the antibodyantigen or the receptor-ligand complexes can be quantified by following the change in the absorbance of photons of light energy spectrophotometrically. In other instances, the binding events, as well as the resultant complexes, may require amplification for better signal recognition. This has been achieved by using various labels comprising enzymes, fluorophores, and radioisotopes, among others. Owing to these advances, immunochemistry techniques applicable in a wide array of fields/disciplines including such analyses in the foods and drugs industry have been developed. The popularity of the antibody-antigen based techniques, since their development by the late 1970s [77], is due to their high level of specificity and sensitivity even in the presence of contaminating materials. Besides, immunochemical methods do not require skilled and highly trained personnel to troubleshoot in case of any problems during separation; they are less labour intensive and consume less time, in which respects they are preferable to both chromatographic and spectrophotometric techniques. The major immunochemical methods used in aflatoxins analysis comprise radioimmunoassay (RIA), enzyme-linked immunosorbent assay (ELISA), immunoaffinity column assay (ICA), and immunosensors. Detailed discussions of the principles as well as the practical applications of these methods are presented under the proceeding subheadings. 


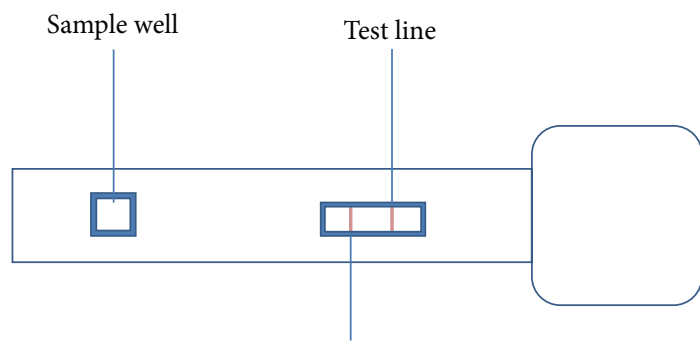

Control line

(a)

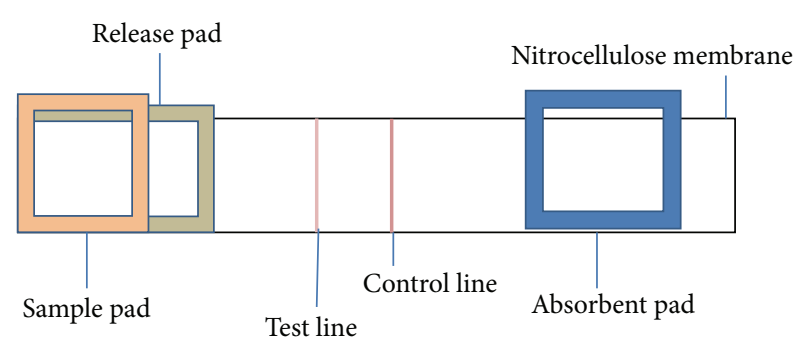

(b)

FIgURE 8: Schematic of a lateral flow device in the dipstick format: (a) external details and (b) internal details.

3.3.1. Radioimmunoassay (RIA). The radioimmunoassay technique relies on the principle of competitive binding between a radioactive-labeled antigen and a nonradioactive antigen. The radioactive-labeled antigen competes with unlabelled nonradioactive antigen for a fixed number of antibody or antigen binding sites on the same antibody [80]. A known quantity of labeled antigen and unknown amount of unlabeled antigen from standards competitively react with a known and limiting amount of the antibody. The amounts of labeled antigen are inversely proportional to the amount of unlabeled antigen in the sample [81]. Radioimmunoassay was the first immunoassay technique to be developed and was applied in the detection of insulin in human blood [82]. Radioimmunoassay has also been used for analysis of aflatoxins in food samples. Langone and van Vunakis [83] reported the use of solid phase radioimmunoassay technique in the determination of aflatoxin $B_{1}$ in peanut and a detection limit of $1 \mu \mathrm{g} / \mathrm{kg}$ was achieved. Similarly, radioimmunoassays have been used for the qualitative and quantitative determination of aflatoxin $B_{1}$ levels $[37,84]$ and aflatoxin $\mathrm{M}_{1}$ levels [82]. The major advantage of radioimmunoassay is the ability to perform multiple analyses simultaneously with high levels of sensitivity and specificity [85]. However, RIAs also suffer from a number of disadvantages: (a) it requires an antigen in a pure state, (b) a radioactive isotope is used as a label and is associated with potential health hazards, and (c) it has problems associated with the storage and disposing of the low-level radioactive waste [86]. These disadvantages have limited the frequent use of RIA in the day to day analysis of aflatoxins.

\subsubsection{Enzyme-Linked Immunosorbent Assay (ELISA). The} potential health hazards related to the use of radioimmunoassay led to the lookout for a safer alternative and a suitable alternative to radioimmunoassay was to replace a radioactive signal with a nonradioactive one. This was achieved by labeling either the antigens or the antibodies with enzymes instead of isotopes. The preparation of enzyme-antigen conjugates and enzyme-antibody conjugates by Avrameas in 1969 [87] paved the way for the enzyme-linked immunosorbent assay (ELISA) development. Enzyme immunoassay (EIA) and typically the ELISA have become the methods of choice for medical diagnostic laboratories, research institutions, and regulatory bodies for quality assessment and proficiencytesting, among others. The principle of enzyme immunoassays is essentially the same as other immunochemical methods; that is, it relies on the specificity of antibodies for antigens and the sensitivity of the assay is increased by labeling either the antibodies or the antigens with an enzyme that can be easily assayed by use of specific substrates. Hence, an antibody immobilized onto a solid support may capture an unlabeled antigen in the analyte, which is subsequently detected by a labeled antibody [86]. The EIA/ELISA principle has generated a whole series of test formats [88]. For instance, competitive enzyme immunoassays format not only is simple to perform but provides a useful measure of either antigen or antibody concentration and is also highly sensitive.

The ELISA technique is currently used in the detection of aflatoxins in agricultural products [89-93] and a number of commercially available ELISA kits based on a competitive immunoassay format are widely used $[8,94,95]$. Most of the kits use horseradish peroxidase (HRP) and alkaline phosphatase (AP) enzymes as labels in analysis of aflatoxins $[96,97]$. The ELISA method offers a number of advantages: (a) it is possible to perform the test on a 96-well assay platform, which means that large number of samples can be analysed simultaneously [95]; (b) ELISA kits are cheap and easy to use and do not require extensive sample cleanup; and (c) there are no inherent health hazards associated with enzyme labels as there are for isotopes. However, the ELISA technique requires multiple washing steps, which may at times prove not only laborious but also time consuming.

3.3.3. Lateral Flow Devices (Immunodipsticks). Immunodipsticks are immunochromatographic assays, also known as lateral flow devices. The principle is based on the use of high sensitivity and specificity of antibody-antigen reactions for the rapid detection of analytes. Lateral flow devices contain a porous membrane which ensures the flow, an absorbent pad that increases the volume of the flowing liquid, a sample pad that ensures contact between the liquid sample and the membrane, and a rigid backing that gives support to the device (Figure 8). Lateral flow devices use labels such as colloidal gold and gold coated with the antibody, which commonly provide red-colored binding zones [95]. The liquid sample added to the sample pad moves towards the extreme end through the membrane by capillary flow to the 


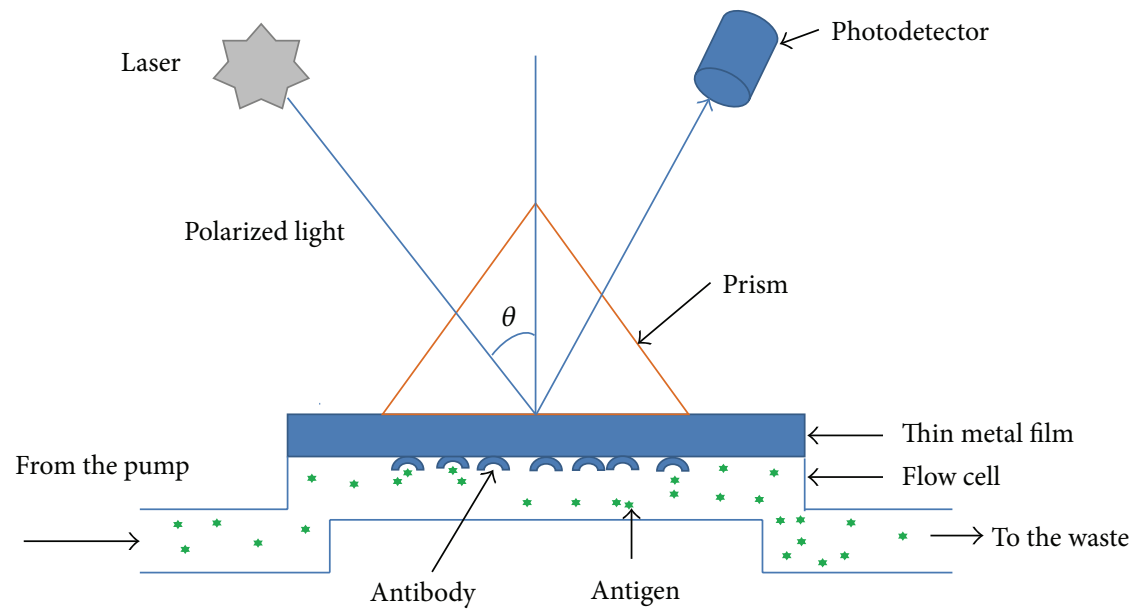

FIGURE 9: Surface plasmon resonance spectroscopy commonly used for the detection of antigen-antibody interactions in a buffered sample.

absorbent pad [26]. When the liquid component containing aflatoxins reaches the gold particles, the sample suspends the gold particles and the aflatoxins bind to the particles, thereby coloring the line red.

Delmulle et al. [38] developed a lateral flow device for detecting aflatoxin $B_{1}$ in pig feed. The device would detect $5 \mu \mathrm{g} / \mathrm{Kg}$ aflatoxin within $10 \mathrm{~min}$, which is within the European Commission (EC) stringent limit fixed for feedstuffs. Another immunochromatographic method was developed by Ho and Wauchope [98]. The assay is based on competition between free $\mathrm{AFB}_{1}$ and $\mathrm{AFB}_{1}$-tagged dye-containing liposomes for the corresponding antibody. The device can detect $18 \mathrm{ng}$ of the aflatoxin in less than 12 minutes. Whereas the device was designed for direct qualitative visual reading, it has also been adapted for use in the optical density scanning mode, which allows for quantitative determination of aflatoxins. Lateral flow devices are easy to use and provide quick onsite detection of aflatoxins within few minutes. They are cost-effective devices that can be adapted for day to day monitoring of aflatoxins

3.3.4. Immunosensors. An immunosensor is a biosensor that uses an antigen or antibody species as biological recognition components coupled to a signal transducer such as graphite, gold, and carbon that help to detect the binding of the complementary species $[99,100]$. With respect to type of signal transduction in use, immunosensors may be grouped into piezoelectric, optical, and electrochemical sensors [39].

(1) Piezoelectric Quartz Crystal Microbalances (QCMs). are label-free devices used for direct detection of antigens. The piezoelectric quartz crystal relies on changes in mass on the electrode surface when an antigen interacts with a cognate antibody immobilized on the quartz crystal surface. Since the change in mass is proportional to the concentration of the antigen-antibody complex, the method permits detection and quantification of the immune complex (Ab-Ag). [101]. Piezoelectric quartz crystal microbalance has been reported for aflatoxin $B_{1}$ analysis. During development, Spinella et al. coated both sides of the QCM sensor with gold electrodes; liquid side was in contact with the solution while the contact side of the crystal was dry. Piezoelectric immunosensor was tested for aflatoxin $\mathrm{B}_{1}$ detection by immobilization of DSP-anti-AFLAB ${ }_{1}$ antibody on gold-coated quartz crystals (AT-cut $/ 5 \mathrm{MHz}$ ). The 3,3'-dithiodipropionic-acid-di-Nhydroxysuccinimide ester (DSP) was used for the covalent binding of the proteins. The sensor was capable of detecting aflatoxin $B_{1}$ concentration in the range of $0.5-10 \mathrm{ppb}$ [102]. Jin et al. [103] also developed quartz crystal microbalance based sensor for detection of aflatoxin $B_{1}$ and their device could detect aflatoxin $B_{1}$ in artificially contaminated milk samples at a concentration range of $0.01-10.0 \mathrm{ng} / \mathrm{mL}$. Quartz crystal microbalance is a very good label-free technology although its use for direct detection of mycotoxins may be a challenge due to the small sizes of most mycotoxins.

(2) Optical Immunosensors. A number of optical immunosensors have been developed for aflatoxins based on different transduction approaches. One of these optical immunosensors already developed for aflatoxin analysis is surface plasmon resonance (SPR) (Figure 9). Surface plasmon resonance (SPR) platform relies on measurement of changes in refractive index produced by the binding of analyte to its biospecific partner immobilized on the sensor surface. When the analyte is flowed over the sensor surface, there is a shift in resonant SPR wavelength, which is proportional to the refractive change at the sensor surface and can be calibrated to the surface concentration of bound analyte [104]. The SPR sensor surface contains a biorecognition layer that selectively binds either an antigen or antibody, which, in turn, causes parallel increase in the mass on the sensor surface that is proportional to an increase in refractive index. The increase in refractive index will be observed as a shift in the resonance angle. The measurable changes in concentration are those due to binding and dissociation of antibody to its target antigen [105].

The operationalization of SPR immunosensor technology for aflatoxin $B_{1}$ detection and quantification has already been attempted by using both monoclonal and polyclonal 
antibodies to aflatoxin $B_{1}$ [106]. The SPR immunosensor immobilized with monoclonal antibodies, however, encountered regeneration problems at the sensor surface due to the high-affinity binding of the monoclonal antibodies. Yet when polyclonal anti-aflatoxin $B_{1}$ antibodies were immobilized onto the sensor surface, regeneration was achieved using solution of $1 \mathrm{M}$ ethanolamine with $20 \%(\mathrm{v} / \mathrm{v})$ acetonitrile, $\mathrm{pH}$ 12.0. Besides, the sensor achieved a linear detection range of $3.0-98.0 \mathrm{ng} / \mathrm{mL}$ with good reproducibility. Van der Gaag et al. [40] have also used the SPR immunosensor for multiple detection of mycotoxins. Therefore, SPR immunosensors should offer label-free detection of aflatoxins if the current regeneration problems are overcome.

Another form of a label-free biosensor operates on an optical waveguide platform. The optical waveguide platform relies on the evanescent fluorescence excitation to measure binding events at the surface of the waveguide [41, 107], and one such technique is the optical waveguide light-mode spectroscopy (OWLS). Typically, the OWLS technique is based on the precise measurement of the resonance angle of a polarized laser light, diffracted by a grating and incoupled into a thin waveguide. Such incoupling resonance occurs at very precise angles depending on the optical parameters of the sensor chips and the complex refractive index of the covering sample medium [108]. The intensity of the incoupled light guided within the waveguide layer by multiple internal reflections is detected by photodiodes. When used to quantify the adsorption of proteins to waveguide surfaces, the platform is coated with a thin layer of materials that have higher refractive index [42]. Such materials would allow for polarized light to exit the original waveguide, undergo total internal reflection (TIR) at the coating-liquid interface, and eventually reenter the waveguide. However, some light traverses the waveguide and this is done at a precise angle that reflects both the properties of the coating layer and sorption/desorption events at the layer-liquid interface [42]. Thus, the measurement of the resonance angle of polarized grating diffracted light, coupled into a thin waveguide, can be used to study the adsorption of macromolecules onto the surface of sensor chips $[105,109]$. Adányi et al. [43] have used OWLS to detect aflatoxin and ochratoxin in both competitive and direct immunoassays. The detection range of 0.5 and $10 \mathrm{ng} / \mathrm{mL}$ of aflatoxins was achieved when barley and wheat flour samples were analysed.

(3) Electrochemical Immunosensors. An electrochemical immunosensor is a device that uses antibodies incorporated into a biorecognition layer to produce electroactive signals detectable by transducers (amplifiers), which generate measurable signals. The signal is generated in the form of a membrane potential when ions bind to a sensing membrane. The potential difference is then measured. A logarithmic relationship exists between the potential difference (pd) and concentration [99]. The signal measurement can be in the form of differential pulse voltammetry, cyclic voltammetry, chronoamperometry, electrochemical impedance spectroscopy, or linear sweep voltammetry [110]. A number of electrochemical immunosensors have been reported to be used in aflatoxins analysis $[44,45,111,112]$ and most of them involve immobilization of antibodies onto the surface of an electrode. Although majority of the electrochemical immunosensors [111,112] developed for aflatoxins analysis use enzymes as active biological component to generate signals, Masoomi et al. [44] developed a nonenzymatic sandwich form of an electrochemical immunosensor. The sensor in the nonenzymatic sandwich type was developed through modification of glassy carbon electrodes using chitosan, gold nanoparticle, anti-aflatoxin $\mathrm{B}_{1}$, and iron III oxide $\left(\mathrm{Fe}_{3} \mathrm{O}_{4}\right)$ magnetic core with a gold shell functionalized with 3-((2-mercaptoethylimino)methyl) benzene-1,2-diol and labeled with $\mathrm{AFB}_{1}$. This immunosensor achieved aflatoxin $B_{1}$ detection range of $0.6-110 \mathrm{ng} / \mathrm{mL}$ and a detection limit of $0.2 \mathrm{ng} / \mathrm{mL}$. Another form of nonenzymatic electrochemical immunosensor was developed by Linting et al. [45]. This type of immunosensor was developed by electrodepositing of graphene oxide and gold nanoparticles, respectively, on the surface of gold electrode. Aflatoxin $B_{1}$ antibody immobilized on the conducting polymer film and ionic liquid and chitosan solution dropped onto this electrode. This immunosensor attained a dynamic range of 3.2-0.32 picomoles and detection limit of one femtomole with excellent long-term stability.

\section{Conclusions}

Various analytical methods employed in analysis of aflatoxins in agricultural food crops and feeds have been explored. While chromatographic methods such as TLC and HPLC are considered the gold standard and are thus the most widely used techniques in aflatoxins analysis, they remain largely cumbersome, requiring extensive sample preparations, let alone very expensive equipment. This makes their routine use in analysis confined to laboratories. It is on the account of such limitations that it was necessary to develop more sensitive and better techniques for aflatoxins analyses. Analytical methods based on spectroscopy and immunochemistry have been added to the earlier chromatographic methods, of which immunoassays emerged as better alternatives for routine and on-site detection of aflatoxins. Improvement in analytical chemistry and recent advances in immunochemistry have led to more specific, sensitive, simple, and rapid immunoassays which have become the method of choice for on-site and routine analysis of mycotoxins in foods and feeds. It worth noting that although many sensitive methods have been described for analysis of aflatoxins, based on immunochemical format, most of them require labeling, as well as skilled and well trained operators. Therefore, the search for simple, label-free, and more rapid and sensitive tools that are based on immune-biosensor format appears to offer, for the near future, versatile, portable, sensitive, and accurate field use devices for aflatoxin detection.

\section{Conflict of Interests}

The authors declare that there is no conflict of interests regarding the publication of this paper. 


\section{Acknowledgments}

The authors thank the Canadian International Development Research Council (IDRC) and Uganda Industrial Research Institute for financially supporting this study which led to this review and Engineer Ocheng Mathew, of the Instrumentation Unit, Technical Development Centre, Uganda Industrial Research Institute, for his technical support.

\section{References}

[1] J. W. Bennett and M. Klich, "Mycotoxins," Clinical Microbiology Reviews, vol. 16, no. 3, pp. 497-516, 2003.

[2] G. C. Dors, S. Caldas, V. Feddern et al., "Aflatoxins: contamination, analysis and control," in Aflatoxins-Biochemistry and Molecular Biology, pp. 415-438, InTech, Shanghai, China, 2011.

[3] H. Gourama and L. B. Bullerman, "Detection of molds in foods and feeds: potential rapid and selective methods," Journal of Food Protection, vol. 58, no. 12, pp. 1389-1394, 1995.

[4] H. S. Hussein and J. M. Brasel, "Toxicity, metabolism, and impact of mycotoxins on humans and animals," Toxicology, vol. 167, no. 2, pp. 101-134, 2001.

[5] J. M. Cullen, P. M. Newberne, D. Eaton, and J. Groopman, "Acute hepatotoxicity of aflatoxins," in The Toxicology of Aflatoxins: Human Health, Veterinary and Agricultural Significance, pp. 3-26, 1993.

[6] W. T. Kok, "Derivatization reactions for the determination of aflatoxins by liquid chromatography with fluorescence detection," Journal of Chromatography B: Biomedical Sciences and Applications, vol. 659, no. 1-2, pp. 127-137, 1994.

[7] M. Ayub and D. Sachan, "Dietary factors affecting aflatoxin bi carcinogenicity," Malaysian Journal of Nutrition, vol. 3, pp. 161197, 1997.

[8] J. Stroka and E. Anklam, "New strategies for the screening and determination of aflatoxins and the detection of aflatoxinproducing moulds in food and feed," TrAC-Trends in Analytical Chemistry, vol. 21, no. 2, pp. 90-95, 2002.

[9] C. P. Wild and P. C. Turner, "The toxicology of aflatoxins as a basis for public health decisions," Mutagenesis, vol. 17, no. 6, pp. 471-481, 2002.

[10] E. P. Gallagher, K. L. Kunze, P. L. Stapleton, and D. L. Eaton, “The kinetics of aflatoxin $\mathrm{B}_{1}$ oxidation by human $\mathrm{cDNA}$-expressed and human liver microsomal cytochromes P450 1A2 and 3A4," Toxicology and Applied Pharmacology, vol. 141, no. 2, pp. 595606, 1996.

[11] M. Vondracek, Z. Xi, P. Larsson et al., "Cytochrome P450 expression and related metabolism in human buccal mucosa," Carcinogenesis, vol. 22, no. 3, pp. 481-488, 2001.

[12] F. P. Guengerich, W. W. Johnson, T. Shimada, Y.-F. Ueng, H. Yamazaki, and S. Langouët, "Activation and detoxication of aflatoxin $\mathrm{B}_{1}$," Mutation Research/Fundamental and Molecular Mechanisms of Mutagenesis, vol. 402, no. 1-2, pp. 121-128, 1998.

[13] G. S. Bbosa, D. Kitya, J. Odda, and J. Ogwal-Okeng, "Aflatoxins metabolism, effects on epigenetic mechanisms and their role in carcinogenesis," Health, vol. 5, no. 10, pp. 14-34, 2013.

[14] W. W. Johnson, H. Yamazaki, T. Shimada, Y.-F. Ueng, and F. P. Guengerich, "Aflatoxin B1 8,9-epoxide hydrolysis in the presence of rat and human epoxide hydrolase," Chemical Research in Toxicology, vol. 10, no. 6, pp. 672-676, 1997.

[15] W. W. Johnson, T. M. Harris, and F. P. Guengerich, "Kinetics and mechanism of hydrolysis of aflatoxin B1 exo-8,9-epoxide and rearrangement of the dihydrodiol," Journal of the American Chemical Society, vol. 118, no. 35, pp. 8213-8220, 1996.

[16] J. D. Hayes, D. J. Judah, and G. E. Neal, "Resistance to aflatoxin B1 is associated with the expression of a novel aldoketo reductase which has catalytic activity towards a cytotoxic aldehyde-containing metabolite of the toxin," Cancer Research, vol. 53, no. 17, pp. 3887-3894, 1993.

[17] L. P. Knight, T. Primiano, J. D. Groopman, T. W. Kensler, and T. R. Sutter, "cDNA cloning, expression and activity of a second human aflatoxin $\mathrm{B}_{1}$-metabolizing member of the aldoketo reductase superfamily, AKR7A3," Carcinogenesis, vol. 20, no. 7, pp. 1215-1223, 1999.

[18] A. Y. Nassar, S. E. Megalla, H. M. Abd El-Fattah, A. H. Hafez, and T. S. El-Deap, "Binding of aflatoxin b1, g1 and M to plasma albumin," Mycopathologia, vol. 79, no. 1, pp. 35-38, 1982.

[19] K.-H. Kiessling, "Biochemical mechanism of action of mycotoxins," Pure and Applied Chemistry, vol. 58, pp. 327-338, 1986.

[20] A. Papadopoulou-Bouraoui, J. Stroka, and E. Anklam, "Comparison of two post-column derivatization systems, ultraviolet irradiation and electrochemical determination, for the liquid chromatographic determination of aflatoxins in food," Journal of AOAC International, vol. 85, no. 2, pp. 411-416, 2002.

[21] C. de Oliveira and P. Germano, "Aflatoxins: current concepts on mechanisms of toxicity and their involvement in the etiology of hepatocellular carcinoma," Revista de Saúde Pública, vol. 31, no. 4, pp. 417-424, 1997.

[22] D. D. Levy, J. D. Groopman, S. E. Lim, M. M. Seidman, and K. H. Kraemer, "Sequence specificity of aflatoxin B1-induced mutations in a plasmid replicated in xeroderma pigmentosum and DNA repair proficient human cells," Cancer Research, vol. 52, no. 20, pp. 5668-5673, 1992.

[23] F. Aguilar, S. P. Hussain, and P. Cerutti, "Aflatoxin B1 induces the transversion of $\mathrm{G} \rightarrow \mathrm{T}$ in codon 249 of the p53 tumor suppressor gene in human hepatocytes," Proceedings of the National Academy of Sciences of the United States of America, vol. 90, no. 18, pp. 8586-8590, 1993.

[24] D. L. Eaton and E. P. Gallagher, "Mechanisms of aflatoxin carcinogenesis," Annual Review of Pharmacology and Toxicology, vol. 34, pp. 135-172, 1994.

[25] M. McLean and M. F. Dutton, "Cellular interactions and metabolism of aflatoxin: an update," Pharmacology \& Therapeutics, vol. 65, no. 2, pp. 163-192, 1995.

[26] P. Li, Q. Zhang, and W. Zhang, "Immunoassays for aflatoxins," TrAC-Trends in Analytical Chemistry, vol. 28, no. 9, pp. 11151126, 2009.

[27] M. N. Pascale, "Detection methods for mycotoxins in cereal grains and cereal products," Zbornik Matice Srpske za Prirodne Nauke, vol. 117, pp. 15-25, 2009.

[28] I. Y. Goryacheva, S. de Saeger, S. A. Eremin, and C. van Peteghem, "Immunochemical methods for rapid mycotoxin detection: evolution from single to multiple analyte screening: a review," Food Additives and Contaminants, vol. 24, no. 10, pp. 1169-1183, 2007.

[29] M. Z. Zheng, J. L. Richard, and J. Binder, "A review of rapid methods for the analysis of mycotoxins," Mycopathologia, vol. 161, no. 5, pp. 261-273, 2006.

[30] I. Balzer, C. Bogdanić, and S. Pepeljnjak, "Rapid thin layer chromatographic method for determining aflatoxin B1, ochratoxin A, and zearalenone in corn," Journal of the Association of Official Analytical Chemists, vol. 61, no. 3, pp. 584-585, 1978. 
[31] D. L. Park, M. W. Trucksess, S. Nesheim, M. Stack, and R. F. Newell, "Solvent-efficient thin-layer chromatographic method for the determination of aflatoxins B1, B2, G1, and G2 in corn and peanut products: collaborative study," Journal of AOAC International, vol. 77, no. 3, pp. 637-646, 1994.

[32] Y. Liang, M. E. Baker, B. T. Yeager, and M. B. Denton, "Quantitative analysis of aflatoxins by high-performance thinlayer chromatography utilizing a scientifically operated chargecoupled device detector," Analytical Chemistry, vol. 68, no. 22, pp. 3885-3891, 1996.

[33] A. Rahmani, S. Jinap, and F. Soleimany, "Qualitative and quantitative analysis of mycotoxins," Comprehensive Reviews in Food Science and Food Safety, vol. 8, no. 3, pp. 202-251, 2009.

[34] M. Kokkonen, M. Jestoi, and A. Rizzo, "Determination of selected mycotoxins in mould cheeses with liquid chromatography coupled tandem with mass spectrometry," Food Additives and Contaminants, vol. 22, no. 5, pp. 449-456, 2005.

[35] B. R. Malone, C. W. Humphrey, T. R. Romer, and J. L. Richard, "Determination of aflatoxins in grains and raw peanuts by a rapid procedure with fluorometric analysis," Journal of AOAC International, vol. 83, no. 1, pp. 95-98, 2000.

[36] T. Pearson, D. Wicklow, E. Maghirang, F. Xie, and F. Dowell, "Detecting aflatoxin in single corn kernels by transmittance and reflectance spectroscopy," Transactions of the American Society of Agricultural Engineers, vol. 44, no. 5, pp. 1247-1254, 2001.

[37] P. Sun and Y. Chu, "A simple solid-phase radioimmunoassay for aflatoxin b1," Journal of Food Safety, vol. 1, pp. 67-75, 1979.

[38] B. S. Delmulle, S. M. D. G. de Saeger, L. Sibanda, I. Barna-Vetro, and C. H. van Peteghem, "Development of an immunoassaybased lateral flow dipstick for the rapid detection of aflatoxin B1 in pig feed," Journal of Agricultural and Food Chemistry, vol. 53, no. 9, pp. 3364-3368, 2005.

[39] P. B. Luppa, L. J. Sokoll, and D. W. Chan, "Immunosensorprinciples and applications to clinical chemistry," Clinica Chimica Acta, vol. 314, no. 1-2, pp. 1-26, 2001.

[40] B. van der Gaag, S. Spath, H. Dietrich et al., "Biosensors and multiple mycotoxin analysis," Food Control, vol. 14, no. 4, pp. 251-254, 2003.

[41] Z. Liron, L. M. Tender, J. P. Golden, and F. S. Ligler, "Voltageinduced inhibition of antigen-antibody binding at conducting optical waveguides," Biosensors and Bioelectronics, vol. 17, no. 67, pp. 489-494, 2002.

[42] H. Yu, C. M. Eggleston, J. Chen, W. Wang, Q. Dai, and J. Tang, "Optical waveguide lightmode spectroscopy (OWLS) as a sensor for thin film and quantum dot corrosion," Sensors, vol. 12, no. 12, pp. 17330-17342, 2012.

[43] N. Adányi, I. A. Levkovets, S. Rodriguez-Gil, A. Ronald, M. Váradi, and I. Szendro, "Development of immunosensor based on OWLS technique for determining Aflatoxin B1 and Ochratoxin A," Biosensors and Bioelectronics, vol. 22, no. 6, pp. 797-802, 2007.

[44] L. Masoomi, O. Sadeghi, M. H. Banitaba, A. Shahrjerdi, and S. S. H. Davarani, "A non-enzymatic nanomagnetic electroimmunosensor for determination of Aflatoxin $B_{1}$ as a model antigen," Sensors and Actuators B: Chemical, vol. 177, pp. 11221127,2013

[45] Z. Linting, L. Ruiyi, L. Zaijun, X. Qianfang, F. Yinjun, and L. Junkang, "An immunosensor for ultrasensitive detection of aflatoxin $\mathrm{B}_{1}$ with an enhanced electrochemical performance based on graphene/conducting polymer/gold nanoparticles/the ionic liquid composite film on modified gold electrode with electrodeposition," Sensors and Actuators B: Chemical, vol. 174, pp. 359-365, 2012.

[46] T. Bertuzzi, S. Rastelli, A. Mulazzi, and A. Pietri, "Evaluation and improvement of extraction methods for the analysis of aflatoxins $B_{1}, B_{2}, G_{1}$ and $G_{2}$ from naturally contaminated maize," Food Analytical Methods, vol. 5, no. 3, pp. 512-519, 2012.

[47] S. L. Taylor, J. W. King, J. L. Richard, and J. I. Greer, "Analyticalscale supercritical fluid extraction of aflatoxin b1 from fieldinoculated corn," Journal of Agricultural and Food Chemistry, vol. 41, no. 6, pp. 910-913, 1993.

[48] J. Stroka, M. Petz, U. Joerissen, and E. Anklam, "Investigation of various extractants for the analysis of aflatoxin $\mathrm{B} 1$ in different food and feed matrices," Food Additives and Contaminants, vol. 16 , no. 8, pp. 331-338, 1999.

[49] I. Arranz, E. Sizoo, H. van Egmond et al., "Determination of aflatoxin B1 in medical herbs: interlaboratory study," Journal of AOAC International, vol. 89, no. 3, pp. 595-605, 2006.

[50] A. Gallo, F. Masoero, T. Bertuzzi, G. Piva, and A. Pietri, "Effect of the inclusion of adsorbents on aflatoxin B-1 quantification in animal feedstuffs," Food Additives and Contaminants-Part A Chemistry, Analysis, Control, Exposure and Risk Assessment, vol. 27, no. 1, pp. 54-63, 2010.

[51] N. A. Lee, S. Wang, R. D. Allan, and I. R. Kennedy, "A rapid aflatoxin $\mathrm{B}_{1}$ Elisa: development and validation with reduced matrix effects for peanuts, corn, pistachio, and soybeans," Journal of Agricultural and Food Chemistry, vol. 52, no. 10, pp. 2746-2755, 2004.

[52] F. Ma, R. Chen, P. Li, Q. Zhang, W. Zhang, and X. Hu, "Preparation of an immunoaffinity column with amino-silica gel microparticles and its application in sample cleanup for aflatoxin detection in agri-products," Molecules, vol. 18, no. 2, pp. 2222-2235, 2013.

[53] P. M. Scott and M. W. Trucksess, "Application of immunoaffinity columns to mycotoxin analysis," Journal of AOAC International, vol. 80, no. 5, pp. 941-949, 1997.

[54] W. L. Shelver, G. L. Larsen, and J. K. Huwe, "Use of an immunoaffinity column for tetrachlorodibenzo- $p$-dioxin serum sample cleanup," Journal of Chromatography B: Biomedical Applications, vol. 705, no. 2, pp. 261-268, 1998.

[55] A. Braithwaite, F. J. Smith, and R. Stock, Chromatographic Methods, Chapman and Hall, 1985.

[56] K. E. Sapsford, C. R. Taitt, S. Fertig et al., "Indirect competitive immunoassay for detection of aflatoxin $B_{1}$ in corn and nut products using the array biosensor," Biosensors and Bioelectronics, vol. 21, no. 12, pp. 2298-2305, 2006.

[57] H. de Iongh, R. Vles, and P. de Vogel, "The occurrence and detection of aflatoxin in food," in Proceedings of the Symposium on Mycotoxins in Foodstuffs, G. H. Wogan, Ed., p. 235, MIT Press, Cambridge, Mass, USA, 1964.

[58] V. Betina, "Thin-layer chromatography of mycotoxins," Journal of Chromatography, vol. 334, no. 3, pp. 211-276, 1985.

[59] H. Gulyas, "Determination of aflatoxins b1, b2, g1, g2 and $\mathrm{ml}$ by high pressure thin layer chromatography," Journal of Chromatography A, vol. 319, pp. 105-111, 1985.

[60] K. M. Abdel-Gawad and A. A. Zohri, "Fungal flora and mycotoxins of six kinds of nut seeds for human consumption in Saudi Arabia," Mycopathologia, vol. 124, no. 1, pp. 55-64, 1993.

[61] Y. M. H. Younis and K. M. Malik, "Tlc and hplc analysis of aflatoxin contamination in sudanese peanut and peanut products," Kuwait Journal of Science and Engineering, vol. 30, no. $1,2003$. 
[62] M. Trucksess, W. Brumley, and S. Nesheim, "Rapid quantitation and confirmation of aflatoxins in corn and peanut butter, using a disposable silica gel column, thin layer chromatography, and gas chromatography/mass spectromety," Journal of the Association of Official Analytical Chemists, vol. 67, no. 5, pp. 973-975, 1984.

[63] E. Papp, K. H-Otta, G. Záray, and E. Mincsovics, "Liquid chromatographic determination of aflatoxins," Microchemical Journal, vol. 73, no. 1-2, pp. 39-46, 2002.

[64] J. Ramesh, G. Sarathchandra, and V. Sureshkumar, "Analysis of feed samples for aflatoxin b1 contamination by hptlc-a validated method," International Journal of Current Microbiology and Applied Sciences, vol. 2, pp. 373-377, 2013.

[65] S. Nawaz, R. D. Coker, and S. J. Haswell, "Development and evaluation of analytical methodology for the determination of aflatoxins in palm kernels," Analyst, vol. 117, no. 1, pp. 67-74, 1992.

[66] P. Li, Q. Zhang, D. Zhang et al., "Aflatoxin measurement and analysis," in Aflatoxins-Detection, Measurement and Control, I. Torres-Pacheco, Ed., pp. 183-208, Intech, Shanghai, China, 2011.

[67] R. Malviya, V. Bansal, O. P. Pal, and P. K. Sharma, "High performance liquid chromatography: a short review," Journal of Global Pharma Technology, vol. 2, no. 5, pp. 22-26, 2010.

[68] Y. Xiang, Y. Liu, and M. L. Lee, "Ultrahigh pressure liquid chromatography using elevated temperature," Journal of Chromatography A, vol. 1104, no. 1-2, pp. 198-202, 2006.

[69] W. T. Kok, T. C. H. van Neer, W. A. Traag, and L. G. T. Tuinstra, "Determination of aflatoxins in cattle feed by liquid chromatography and post-column derivatization with electrochemically generated bromine," Journal of Chromatography A, vol. 367, pp. 231-236, 1986.

[70] S. M. Herzallah, "Determination of aflatoxins in eggs, milk, meat and meat products using HPLC fluorescent and UV detectors," Food Chemistry, vol. 114, no. 3, pp. 1141-1146, 2009.

[71] M. Takino and T. Tanaka, Determination of Aflatoxins in Food by LC-MS/MS, Agilent Technologies, 2008.

[72] R. F. Boyer, Modern Experimental Biochemistry, Benjamin/Cummings Publishing Company, 1993.

[73] M. N. Pascale, "Detection methods for mycotoxins in cereal grains and cereal products," Matica Srpska Proceedings for Natural Sciences, vol. 117, pp. 15-25, 2009.

[74] P. Scott, "Mycotoxin methodology," Food Additives \& Contaminants, vol. 12, no. 3, pp. 395-403, 1995.

[75] Y. Liang, C. Zhang, and L. Liu, "Chromatographic analysis of mycotoxins," Zhongguo Weisheng Jianyan Zazhi, vol. 15, p. 1273, 2005.

[76] H. Petterson and W. Langseth, "Intercomparison of trichothecenes analysis and feasibility to produce certified calibrants," EU Reports EUR 20285, European Commission BCR Information Project, 2002.

[77] D. Babu, Rapid and Sensitive Detection of Aflatoxin in Animal Feeds and Food Grains Using Immunomagnetic Bead Based Recovery and Real-Time Immuno Quantitative PCR (RT-iqPCR) Assay, Oklahoma State University, 2010.

[78] M. E. S. Mirghani, Y. B. C. Man, S. Jinap, B. S. Baharin, and J. Bakar, "A new method for determining aflatoxins in groundnut and groundnut cake using Fourier transform infrared spectroscopy with attenuated total reflectance," Journal of the American Oil Chemists' Society, vol. 78, no. 10, pp. 985-992, 2001.

[79] A. Sargent and O. A. Sadik, "Monitoring antibody-antigen reactions at conducting polymer-based immunosensors using impedance spectroscopy," Electrochimica Acta, vol. 44, no. 26, pp. 4667-4675, 1999.

[80] S. A. Berson and R. S. Yalow, "General principles of radioimmunoassay," Clinica Chimica Acta, vol. 22, no. 1, pp. 51-69, 1968.

[81] D. S. Skelley, L. P. Brown, and P. K. Besch, "Radioimmunoassay.", Clinical Chemistry, vol. 19, no. 2, pp. 146-186, 1973.

[82] P. Rauch, L. Fukal, J. Prošek, P. Březina, and J. Káš, "Radioimmunoassay of aflatoxin $\mathrm{M}_{1}$," Journal of Radioanalytical and Nuclear Chemistry, vol. 117, no. 3, pp. 163-169, 1987.

[83] J. J. Langone and H. van Vunakis, "Aflatoxin B1: specific antibodies and their use in radioimmunoassay," Journal of the National Cancer Institute, vol. 56, no. 3, pp. 591-595, 1976.

[84] S. Tsuboi, T. Nakagawa, M. Tomita et al., "Detection of aflatoxin B1 in serum samples of male Japanese subjects by radioimmunoassay and high-performance liquid chromatography," Cancer Research, vol. 44, no. 3, pp. 1231-1234, 1984.

[85] T. C. Tseng, C. Chow, and G. Waller, "Immunoassay in mycotoxin research," in Phytochemical Ecology: Allelochemicals, Mycotoxins and Insect Phenomones and Allomones, p. 363, 1989.

[86] R. Twyman, Immunoassays, applications, 2005.

[87] S. Avrameas, "Coupling of enzymes to proteins with glutaraldehyde. Use of the conjugates for the detection of antigens and antibodies," Immunochemistry, vol. 6, no. 1, pp. 43-52, 1969.

[88] R. M. Lequin, "Enzyme immunoassay (eia)/enzyme-linked immunosorbent assay (elisa)," Clinical Chemistry, vol. 51, pp. 2415-2418, 2005.

[89] V. Anjaiah, V. Mehan, S. Jayanthi, D. Reddy, and D. McDonald, "Enzyme-linked immunosorbent assay (elisa) for aflatoxin b1 estimation in groundnuts," 1989.

[90] K. T. Devi, M. Mayo, K. Reddy et al., "Production and characterization of monoclonal antibodies for aflatoxin B1," Letters in Applied Microbiology, vol. 29, no. 5, pp. 284-288, 1999.

[91] K. Thirumala-Devi, M. A. Mayo, A. J. Hall et al., "Development and application of an indirect competitive enzymelinked immunoassay for aflatoxin M1 in milk and milk-based confectionery," Journal of Agricultural and Food Chemistry, vol. 50, no. 4, pp. 933-937, 2002.

[92] O. Kawamura, S. Nagayama, S. Sato, K. Ohtani, I. Ueno, and Y. Ueno, "A monoclonal antibody-based enzyme-linked immunosorbent assay of aflatoxin B 1 in peanut products," Mycotoxin Research, vol. 4, no. 2, pp. 75-88, 1988.

[93] D. Ondiekil, S. T. Lutta, M. O. Okoth, and P. Kering, "Rapid assessment of aflatoxin contamination of groundnuts by thin layer chromatography and competitive enzyme linked immunosorbent assay from selected divisions of Busia county in Kenya," African Journal of Food Science and Technology, vol. 5, no. 1, pp. 12-20, 2014.

[94] A. Ostadrahimi, F. Ashrafnejad, A. Kazemi et al., "Aflatoxin in raw and salt-roasted nuts (pistachios, peanuts and walnuts) sold in markets of tabriz, iran," Jundishapur Journal of Microbiology, vol. 7, no. 1, Article ID e8674, 2014.

[95] B. Huybrechts, Evaluation of Immunoassay Kits for Aflatoxin Determination in Corn \& Rice, CODA-CERVA, National Reference Laboratory on Mycotoxins, 2011.

[96] J. J. Pestka, P. K. Gaur, and F. S. Chu, "Quantitation of aflatoxin $\mathrm{B} 1$ and aflatoxin B1 antibody by an enzyme-linked immunosorbent microassay," Applied and Environmental Microbiology, vol. 40, no. 6, pp. 1027-1031, 1980.

[97] D. L. Park, B. M. Miller, L. P. Hart et al., "Enzyme-linked immunosorbent assay for screening aflatoxin B1 in cottonseed products and mixed feed: collaborative study," Journal of the 
Association of Official Analytical Chemists, vol. 72, no. 2, pp. 326-332, 1989.

[98] J.-A. Ho and R. Wauchope, "A strip liposome immunoassay for aflatoxin $\mathrm{B}_{1}$," Analytical Chemistry, vol. 74, no. 7, pp. 1493-1496, 2002.

[99] C. L. Morgan, D. J. Newman, and C. P. Price, "Immunosensors: technology and opportunities in laboratory medicine," Clinical Chemistry, vol. 42, no. 2, pp. 193-209, 1996.

[100] F. Ricci, G. Volpe, L. Micheli, and G. Palleschi, "A review on novel developments and applications of immunosensors in food analysis," Analytica Chimica Acta, vol. 605, no. 2, pp. 111-129, 2007.

[101] L. Zhou, X. He, D. He, K. Wang, and D. Qin, "Biosensing technologies for Mycobacterium tuberculosis detection: status and new developments," Clinical and Developmental Immunology, vol. 2011, Article ID 193963, 8 pages, 2011.

[102] K. Spinella, L. Mosiello, G. Palleschi, and F. Vitali, "Development of a qcm (quartz crystal microbalance) biosensor to the detection of aflatoxin b1," Open Journal of Applied Biosensor, vol. 2, no. 4, pp. 112-119, 2013.

[103] X. Jin, X. Liu, L. Chen, J. Jiang, G. Shen, and R. Yu, "Biocatalyzed deposition amplification for detection of aflatoxin $\mathrm{B}_{1}$ based on quartz crystal microbalance," Analytica Chimica Acta, vol. 645, no. 1-2, pp. 92-97, 2009.

[104] H. Vaisocherová, K. Mrkvová, M. Piliarik, P. Jinoch, M. Šteinbachová, and J. Homola, "Surface plasmon resonance biosensor for direct detection of antibody against Epstein-Barr virus," Biosensors and Bioelectronics, vol. 22, no. 6, pp. 10201026, 2007.

[105] M. A. Brusatori, Y. Tie, and P. R. van Tassel, "Protein adsorption kinetics under an applied electric field: an optical waveguide lightmode spectroscopy study," Langmuir, vol. 19, no. 12, pp. 5089-5097, 2003.

[106] S. J. Daly, G. J. Keating, P. P. Dillon et al., "Development of surface plasmon resonance-based immunoassay for aflatoxin $\mathrm{B}_{1}$," Journal of Agricultural and Food Chemistry, vol. 48, no. 11, pp. 5097-5104, 2000.

[107] C. A. Rowe-Taitt, J. W. Hazzard, K. E. Hoffman, J. J. Cras, J. P. Golden, and F. S. Ligler, "Simultaneous detection of six biohazardous agents using a planar waveguide array biosensor," Biosensors and Bioelectronics, vol. 15, no. 11-12, pp. 579-589, 2000.

[108] A. Székács, N. Adányi, I. Székács, K. Majer-Baranyi, and I. Szendrő, "Optical waveguide light-mode spectroscopy immunosensors for environmental monitoring," Applied Optics, vol. 48, no. 4, pp. B151-B158, 2009.

[109] G. L. Duveneck, A. P. Abel, M. A. Bopp, G. M. Kresbach, and M. Ehrat, "Planar waveguides for ultra-high sensitivity of the analysis of nucleic acids," Analytica Chimica Acta, vol. 469, no. 1, pp. 49-61, 2002.

[110] A.-L. Välimaa, A. T. Kivistö, P. I. Leskinen, and M. T. Karp, "A novel biosensor for the detection of zearalenone family mycotoxins in milk," Journal of Microbiological Methods, vol. 80, no. 1, pp. 44-48, 2010.

[111] J. H. Owino, O. A. Arotiba, N. Hendricks et al., "Electrochemical immunosensor based on polythionine/gold nanoparticles for the determination of aflatoxin $\mathrm{B}_{1}$," Sensors, vol. 8, no. 12, pp. 8262-8274, 2008.

[112] Y. Liu, Z. Qin, X. Wu, and H. Jiang, "Immune-biosensor for aflatoxin $\mathrm{B} 1$ based bio-electrocatalytic reaction on micro-comb electrode," Biochemical Engineering Journal, vol. 32, no. 3, pp. 211-217, 2006. 

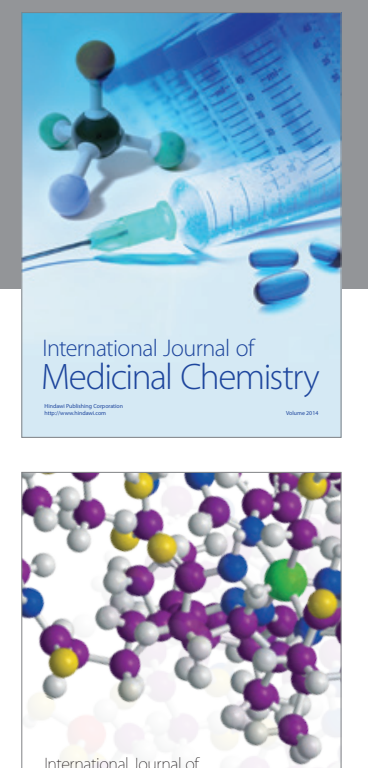

\section{Carbohydrate} Chemistry

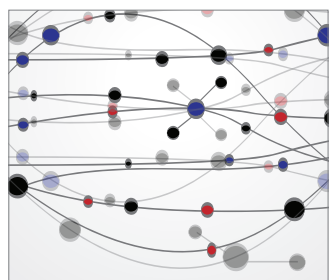

The Scientific World Journal
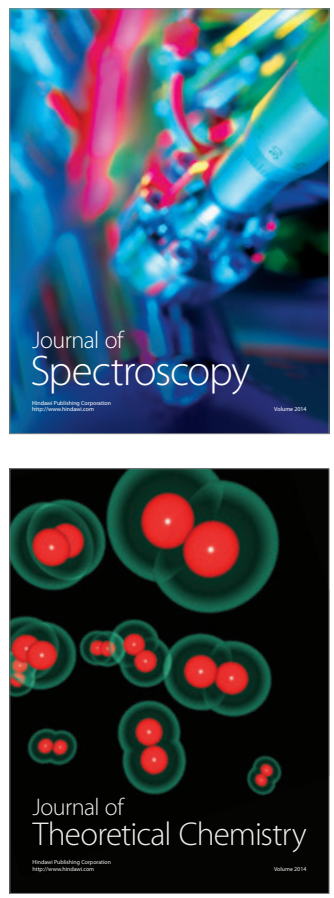
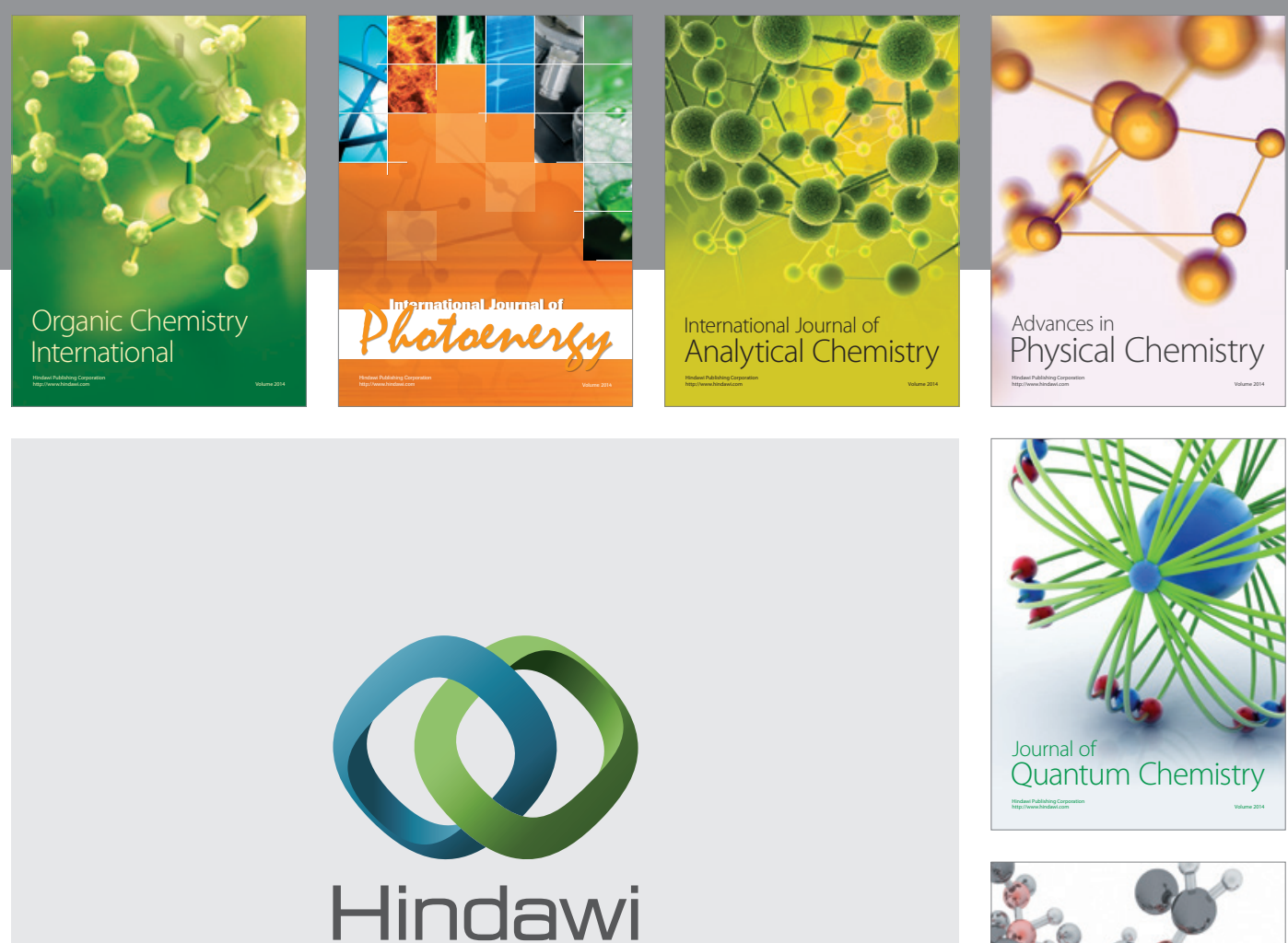

Submit your manuscripts at

http://www.hindawi.com

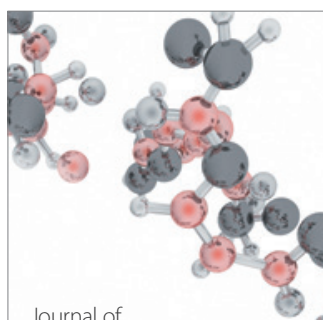

Analytical Methods

in Chemistry

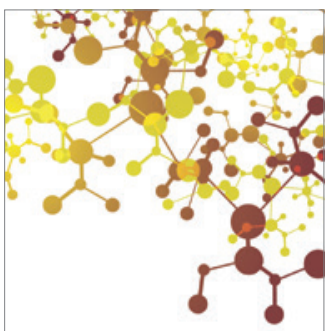

Journal of

Applied Chemistry

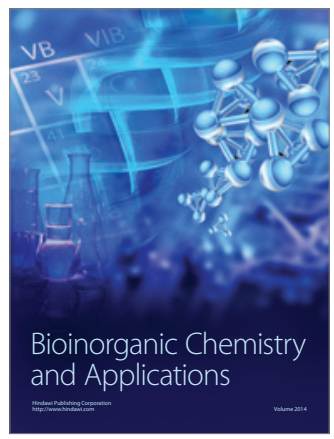

Inorganic Chemistry
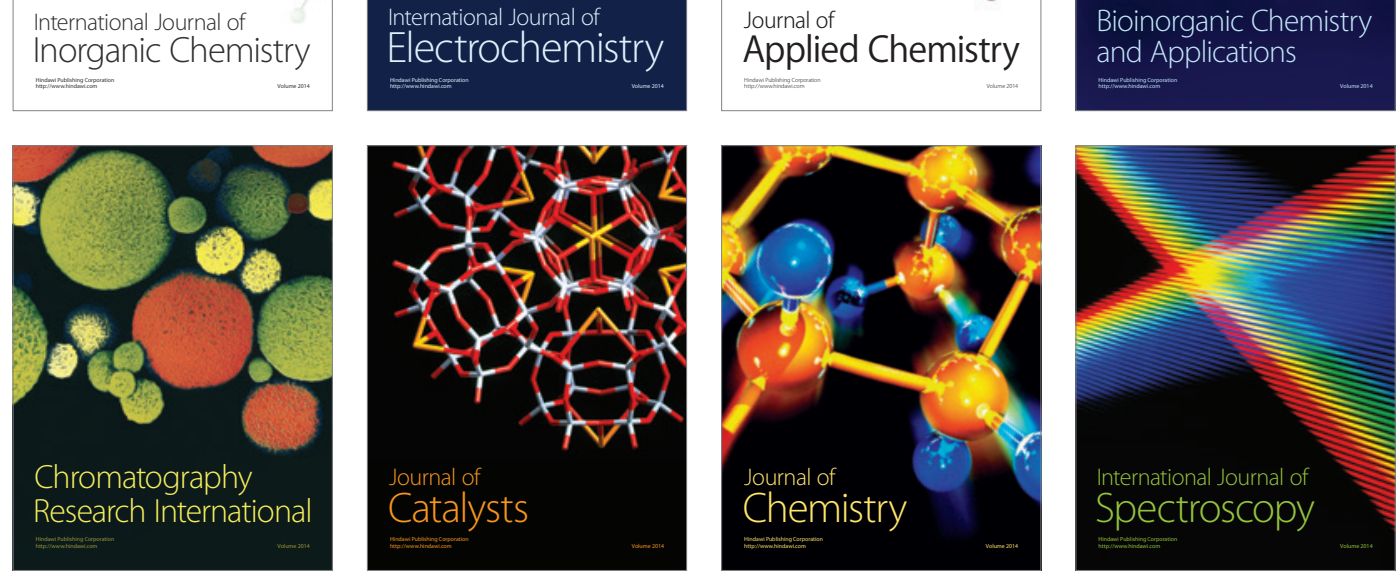